\title{
Types of Solar Cells and Application
}

\author{
Askari Mohammad Bagher', Mirzaei Mahmoud Abadi Vahid², Mirhabibi Mohsen ${ }^{1}$ \\ ${ }^{1}$ Department of Physics, Payame Noor University, Tehran, Iran \\ ${ }^{2}$ Faculty of Physics, Shahid Bahonar University, Kerman, Iran
}

Email address:

mb_askari@yahoo.com (Askari M. B.)

\section{To cite this article:}

Askari Mohammad Bagher, Mirzaei Mahmoud Abadi Vahid, Mirhabibi Mohsen. Types of Solar Cells and Application. American Journal of Optics and Photonics. Vol. 3, No. 5, 2015, pp. 94-113. doi: 10.11648/j.ajop.20150305.17

\begin{abstract}
A solar cell is an electronic device which directly converts sunlight into electricity. Light shining on the solar cell produces both a current and a voltage to generate electric power. This process requires firstly, a material in which the absorption of light raises an electron to a higher energy state, and secondly, the movement of this higher energy electron from the solar cell into an external circuit. The electron then dissipates its energy in the external circuit and returns to the solar cell. A variety of materials and processes can potentially satisfy the requirements for photovoltaic energy conversion, but in practice nearly all photovoltaic energy conversion uses semiconductor materials in the form of a p-n junction. With regard to the development of sustainable energy, such as solar energy, in this article we will Study types of solar cells and their applications.
\end{abstract}

Keywords: Solar Cells, Semiconductor Materials, Sustainable Energy

\section{Introduction}

The Earth receives an incredible supply of solar energy. The sun, an average star, is a fusion reactor that has been burning over 4 billion years. It provides enough energy in one minute to supply the world's energy needs for one year. In one day, it provides more energy than our current population would consume in 27 years. In fact, "The amount of solar radiation striking the earth over a three-day period is equivalent to the energy stored in all fossil energy sources." Solar energy is a free, inexhaustible resource, yet harnessing it is a relatively new idea. Considering that "the first practical solar cells were made less than 30 years ago," we have come a long way. The prolongation of solar professional companies designing unique and specific solar power systems for individual homes means there is no longer an excuse not to consider solar power for your home. The biggest jumps in efficiency came "with the advent of the transistor and accompanying semiconductor technology. There are several advantages of photovoltaic solar power that make it "one of the most promising renewable energy sources in the world." It is non-polluting, has no moving parts that could break down, requires little maintenance and no supervision, and has a life of 20-30 years with low running costs. It is especially unique because no large-scale installation is required. Remote areas can easily produce their own supply of electricity by constructing as small or as large of a system as needed. Solar power generators are simply distributed to homes, schools, or businesses, where their assembly requires no extra development or land area and their function is safe and quiet. As communities grow, more solar energy capacity can be added. Solar energy is most sought today in developing countries, the fastest growing segment of the photovoltaic's market. People go without electricity as the sun beats down on the land, making solar power the obvious energy choice. "Governments are finding its modular, decentralized character ideal for filling the electric needs of the thousands of remote villages in their countries." It is much more practical than the extension of expensive power lines into remote areas, where people do not have the money to pay for conventional electricity. There are only two primary disadvantages to using solar power: amount of sunlight and cost of equipment. The amount of sunlight a location receives "varies greatly depending on geographical location, time of day, season and clouds. Considering the importance of the use of solar cells and efficient use of solar energy, in this article we will examine the different types of solar cells.

A solar cell, or photovoltaic cell, is an electrical device that converts the energy of light directly into electricity by the photovoltaic effect, which is a physical and chemical phenomenon.[1] It is a form of photoelectric cell, defined as a device whose electrical characteristics, such as current, voltage, or resistance, vary when exposed to light. Solar cells 
are the building blocks of photovoltaic modules, otherwise known as solar panels. Solar cells are described as being photovoltaic irrespective of whether the source is sunlight or an artificial light. They are used as a photo detector (for example infrared detectors), detecting light or other electromagnetic radiation near the visible range, or measuring light intensity.

The operation of a photovoltaic (PV) cell requires 3 basic attributes:

1. The absorption of light, generating either electron-hole pairs or exactions.

2. The separation of charge carriers of opposite types.

3 . The separate extraction of those carriers to an external circuit.

\section{Types of Solar Cells and Application}

Solar cells are typically named after the semiconducting material they are made of. These materials must have certain characteristics in order to absorb sunlight. Some cells are designed to handle sunlight that reaches the Earth's surface, while others are optimized for use in space. Solar cells can be made of only one single layer of light-absorbing material (single-junction) or use multiple physical configurations (multi-junctions) to take advantage of various absorption and charge separation mechanisms. Solar cells can be classified into first, second and third generation cells. The first generation cells - also called conventional, traditional or wafer-based cells - are made of crystalline silicon, the commercially predominant PV technology, that includes materials such as polysilicon and monocrystalline silicon. Second generation cells are thin film solar cells, that include amorphous silicon, CdTe and CIGS cells and are commercially significant in utility-scale photovoltaic power stations, building integrated photovoltaics or in small standalone power system. The third generation of solar cells includes a number of thin-film technologies often described as emerging photovoltaics - most of them have not yet been commercially applied and are still in the research or development phase. Many use organic materials, often organometallic compounds as well as inorganic substances. Despite the fact that their efficiencies had been low and the stability of the absorber material was often too short for commercial applications, there is a lot of research invested into these technologies as they promise to achieve the goal of producing low-cost, high-efficient solar cells.

"First generation" panels include silicon solar cells. They are made from a single silicon crystal (mono-crystalline), or cut from a block of silicon that is made up of many crystals (multi-crystalline - shown at right).

"Second generation" thin-film solar cells are less expensive to produce than traditional silicon solar cells as they require a decreased amount of materials for construction. The thin-film PV cells are, just as the name implies, a physically thin technology that has been applied to photovoltaics. They are only slightly less efficient than other types but do require more surface area to generate the same amount of power. [2]

The following are the different types of solar cells.

\subsection{Amorphous Silicon Solar Cell (A-Si)}

Amorphous silicon (a-Si) is the non-crystalline form of silicon. It is the most well developed of the thin film technologies having been on the market for more than 15 years. It is widely used in pocket calculators, but it also powers some private homes, buildings, and remote facilities. United Solar Systems Corp. (UniSolar) pioneered amorphous-silicon solar cells and remains a major maker today, as does Sharp and Sanyo. Amorphous silicon panels are formed by vapor-depositing a thin layer of silicon material - about 1 micrometer thick - on a substrate material such as glass or metal. Amorphous silicon can also be deposited at very low temperatures, as low as 75 degrees Celsius, which allows for deposition on plastic as well.In its simplest form, the cell structure has a single sequence of $\mathrm{p}$-i$\mathrm{n}$ layers. However, single layer cells suffer from significant degradation in their power output (in the range 15-35\%) when exposed to the sun. The mechanism of degradation is called the Staebler-Wronski Effect, after its discoverers. Better stability requires the use of a thinner layers in order to increase the electric field strength across the material. However, this reduces light absorption, hence cell efficiency. This has led the industry to develop tandem and even triple layer devices that contain p-i-n cells stacked one on top of the other. One of the pioneers of developing solar cells using amorphous silicon is Uni-Solar. They use a triple layer system (see illustration below) that is optimized to capture light from the full solar spectrum)As you can see from the illustration, the thickness of the solar cell is just 1 micron, or about $1 / 300$ th the size of mono-crystalline silicon solar cell. While crystalline silicon achieves a yield of about 18 percent, amorphous solar cells' yield remains at around 7 percent. The low efficiency rate is partly due to the Staebler-Wronski effect, which manifests itself in the first hours when the panels are exposed to sunlight, and results in a decrease in the energy yield of an amorphous silicon panel from 10 percent to around 7 percent. The principal advantage of amorphous silicon solar cells is their lower manufacturing costs, which makes these cells very cost competitive.

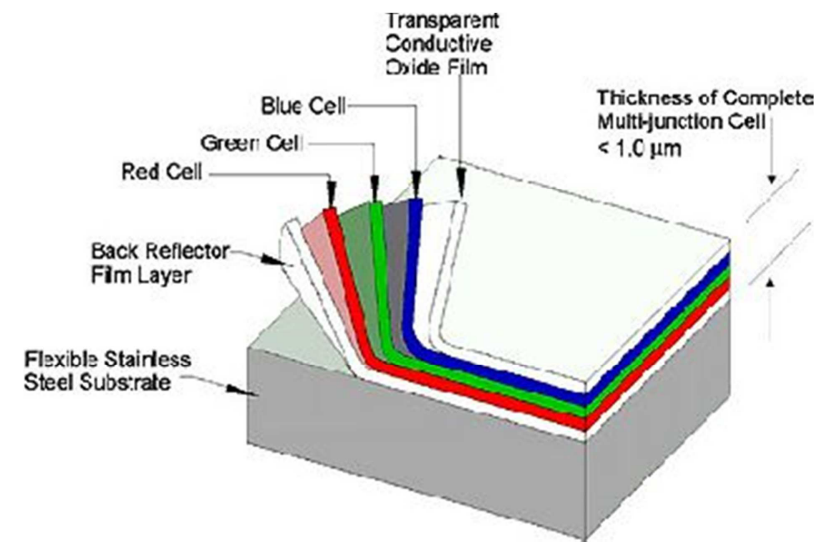

Fig. 1. Amorphous silicon is Uni-Solar. They use a triple layer system. 


\subsection{Biohybrid Solar Cell}

A biohybrid solar cell is a solar cell made using a combination of organic matter (photosystem I) and inorganic matter. Biohybrid solar cells have been made by a team of researchers at Vanderbilt University. The team used the photosystem I (a photoactive protein complex located in the thylakoid membrane) to recreate the natural process of photosynthesis to obtain a greater efficiency in solar energy conversion. These biohybrid solar cells are a new type of renewable energy.[3][4]

Multiple layers of photosystem I gather photonic energy, convert it into chemical energy and create a current that goes through the cell. The cell itself consists of many of the same non-organic materials that are found in other solar cells with the exception of the injected photosystem I complexes which are introduced and gathered for several days in the gold layer. After days the photosytem I are made visible and appear as a thin green film. It is this thin film that helps and improves the energy conversion. The biohybrid cell however, is still in the research phase. The team from Vanderbilt University began conducting research on the photosynthesis when they began to see and focus on the photosystem I protein. After seeing how widely available and efficient the protein was at solar conversion they began to look to incorporate and improve different technologies. The team used spinach as their source for the photosystem I. Thylakoid membranes were isolated and then went into a purification process to separate the photosystem I from the thylakoid membrane. Their research resulted in a greatly improved electrical current (1000 times greater) compared to those previous made by other solar cells. The team has been gathering a group of undergraduate engineers to help build the first prototype of the biohybrid solar cell. The team has also come up with a second design of the protein complex the photosystem II.

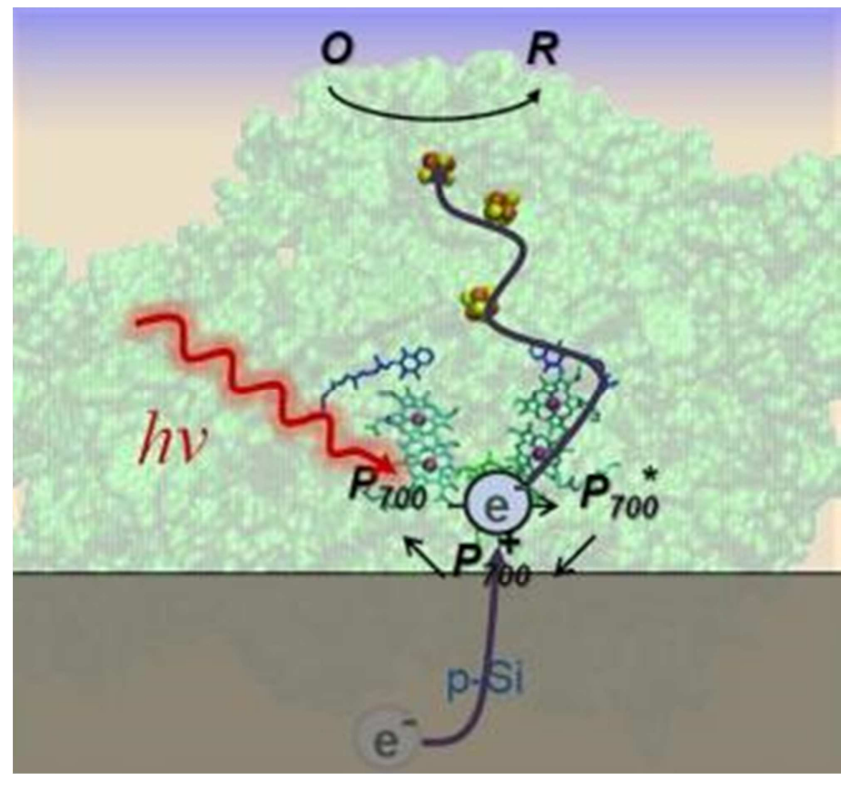

Fig. 2. Making Multilayered Bio-Hybrid Solar cells.

\subsection{Buried Contact Solar Cell}

The buried contact solar cell is a high efficiency commercial solar cell technology based on a plated metal contact inside a laser-formed groove. The buried contact technology overcomes many of the disadvantages associated with screen-printed contacts and this allows buried contact solar cell to have performance up to $25 \%$ better than commercial screen-printed solar cells. A schematic of a buried contact solar cell is shown in the figure below.

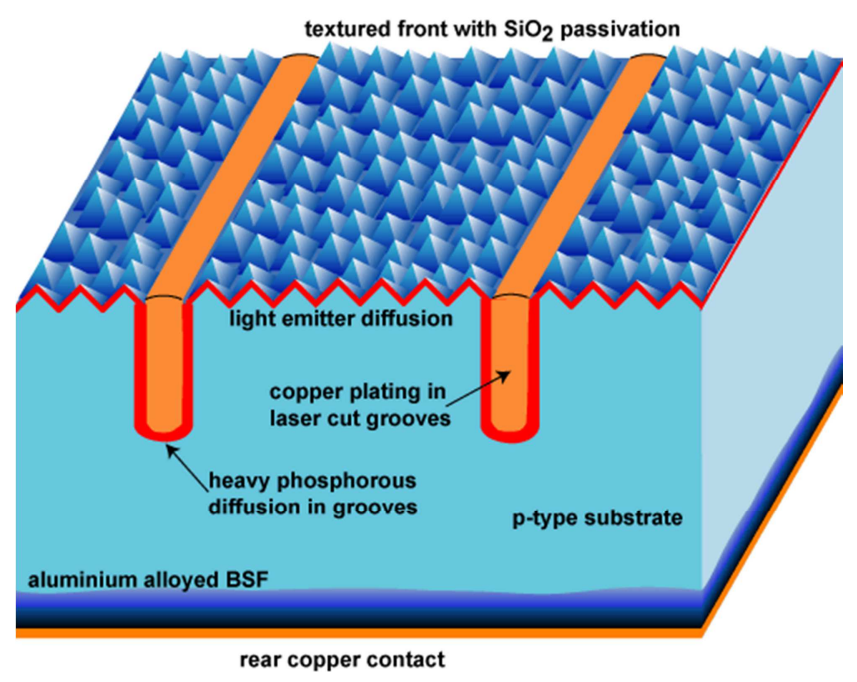

Fig. 3. Cross-section of Laser Grooved, Buried Contact Solar Cell.

A key high efficiency feature of the buried contact solar cell is that the metal is buried in a laser-formed groove inside the silicon solar cell. This allows for a large metal height-towidth aspect ratio. A large metal contact aspect ratio in turn allows a large volume of metal to be used in the contact finger, without having a wide strip of metal on the top surface. Therefore, a high metal aspect ratio allows a large number of closely spaced metal fingers, while still retaining a high transparency. For example, on a large area device, a screen printed solar cell may have shading losses as high as 10 to $15 \%$, while in a buried contact structure, the shading losses will only be 2 to $3 \%$. These lower shading losses allow low reflection and therefore higher short-circuit currents. In addition to good reflection properties, the buried contact technology also allows low parasitic resistance losses due to its high metal aspect ratio, its fine finger spacing and its plated metal for the contacts. As shown in the Emitter Resistance page, the emitter resistance is reduced in a buried contact solar cell since narrower finger spacing dramatically reduces the emitter resistance losses. The metal grid resistance is also low since the finger resistance is reduced by the large volume of metal in the grooves and by the use of copper, which has a lower resistivity than the metal paste used in screen printing. As well, the contact resistance of a buried contact solar cell is lower than that in screen printed solar cells due to the formation of a nickel silicide at the semiconductor-metal interface and the large metal-silicon contact area. Overall, these reduced resistive losses allow large area solar cells with high FFs. 
When compared to a screen-printed cell, the metalization scheme of a buried contact solar cell also improves the cell's emitter. To minimise resistive losses, the emitter region of a screen-printed solar cell is very heavily doped and results in a "dead" layer at the surface of the solar cell. Since emitter losses are low in a buried contact structure, the emitter doping can be optimized for high open-circuit voltages and short-circuit currents. Furthermore, a buried contact structure includes a self-aligned, selective emitter, which thereby reduces the contact recombination and also contributes to high open-circuit voltages. The efficiency advantages of buried contact technology provide significant cost and performance benefits. In terms of $\$ / \mathrm{W}$, the cost of a buried contact solar cell is the same as a screen-printed solar cell [8] However, due to the inclusion of certain area-related costs as well as fixed costs in a PV system, a higher efficiency solar cell technology results in lower cost electricity. An additional advantage of buried contact technology is that it can be used for concentrator systems [5].

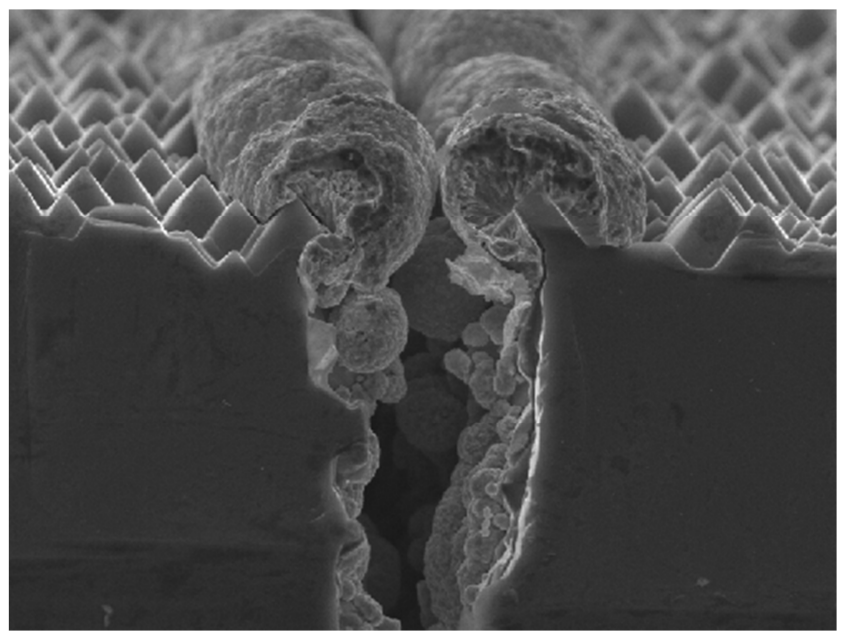

Fig. 4. Cross section of a partially plated laser groove.

\subsection{Cadmium Telluride Solar Cell (CdTe)}

Cadmium telluride (CdTe) photovoltaics describes a photovoltaic (PV) technology that is based on the use of cadmium telluride, a thin semiconductor layer designed to absorb and convert sunlight into electricity.[10] Cadmium telluride PV is the only thin film technology with lower costs than conventional solar cells made of crystalline silicon in multi-kilowatt systems.[6][7][8]

On a lifecycle basis, CdTe PV has the smallest carbon footprint, lowest water use and shortest energy payback time of all solar technologies.[9][10][11] CdTe's energy payback time of less than a year enables for faster carbon reductions without short-term energy deficits. The toxicity of cadmium is an environmental concern mitigated by the recycling of CdTe modules at the end of their life time,[12] though there are still uncertainties[13][14] and the public opinion is skeptical towards this technology.[15][16] The usage of rare materials may also become a limiting factor to the industrial scalability of CdTe technology in the mid-term future. The rare abundance of tellurium - of which telluride is the anionic form-is comparable to that of platinum in the earth's crust and contributes significantly to the module's cost.[17]CdTe photovoltaics is used in some of the world's largest photovoltaic power stations, such as the Topaz Solar Farm. With a share of $5.1 \%$ of worldwide PV production, CdTe technology accounted for more than half of the thin film market in 2013.[18] A prominent manufacturer of CdTe thin film technology is the company First Solar, based in Tempe, Arizona.

\subsection{Toxicity of Cadmium}

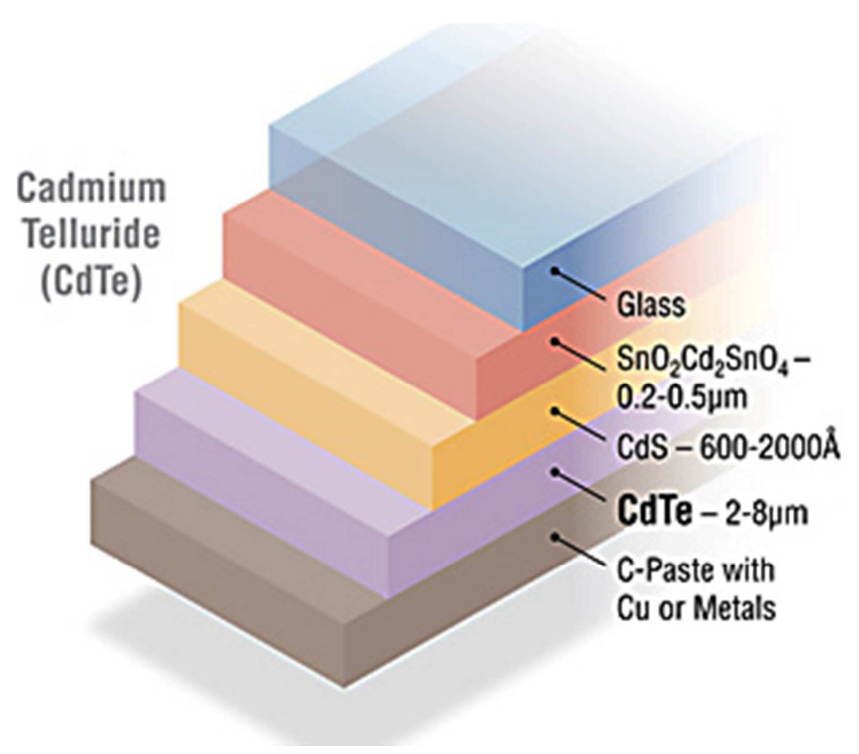

Fig. 5. Graphic showing the five layers that comprise CdTe solar cells.

Cadmium is one of the top 6 deadliest and toxic materials known. However, CdTe appears to be less toxic than elemental cadmium, at least in terms of acute exposure.This is not to say it is harmless. Cadmium telluride is toxic if ingested, if its dust is inhaled, or if it is handled improperly (i.e. without appropriate gloves and other safety precautions). The toxicity is not solely due to the cadmium content. One study found that the highly reactive surface of cadmium telluride quantum dots triggers extensive reactive oxygen damage to the cell membrane, mitochondria, and cell nucleus. In addition, the cadmium telluride films are typically recrystallized in a toxic compound of cadmium chloride. The disposal and long term safety of cadmium telluride is a known issue in the large-scale commercialization of cadmium telluride solar panels. Serious efforts have been made to understand and overcome these issues. Researchers from the U.S. Department of Energy's Brookhaven National Laboratory have found that large-scale use of CdTe PV modules does not present any risks to health and the environment, and recycling the modules at the end of their useful life resolves any environmental concerns. During their operation, these modules do not produce any pollutants, and furthermore, by displacing fossil fuels, they offer great environmental benefits. CdTe PV modules appear to be more environmentally friendly than all other current uses of 
Cd.The approach to CdTe safety in the European Union and China is however, much more cautious: cadmium and cadmium compounds are considered as toxic carcinogens in EU whereas China regulations allow $\mathrm{Cd}$ products for export only. The issue about regulating the use of Cadmium Telluride is currently being discussed in Europe. At the present time - the most common opinion is that the use of Cadmium Terlluride in residential / industrial rooftop installations does not pose a major environmental problem. [19]

\subsection{Concentrated PV Cell (CVP and HCVP)}

Following the sun. A Concentrating Photovoltaic (CPV) system converts light energy into electrical energy in the same way that conventional photovoltaic technology does, but uses an advanced optical system to focuses a large area of sunlight onto each cell for maximum efficiency. Different CPV designs exist, sometimes differentiated by the concentration factor, such as low-concentration (LCPV) and high concentration (HCPV). Concentrator photovoltaic's (CPV) is a photovoltaic technology that generates electricity from sunlight. Contrary to conventional photovoltaic systems, it uses lenses and curved mirrors to focus sunlight onto small, but highly efficient, multi-junction (MJ) solar cells. In addition, CPV systems often use solar trackers and sometimes a cooling system to further increase their efficiency.[20]:30 Ongoing research and development is rapidly improving their competitiveness in the utility-scale segment and in areas of high solar insulation.

CPV technology has been around since the 70s. Recent technological advancements have enabled CPV to reach viability and compete with traditional fossil fuel plants, such as coal, natural gas, and oil, when installed in regions of the world with sunny and dry climates. Concentrating photovoltaic systems work by converting solar light into electricity. Traditional rooftop solar modules rely on the same basic concept to generate electricity. CPV systems have an optical component, which "concentrates" significant amounts of sunlight onto "multi-junction" solar cells. Especially High concentrating photovoltaic (HCPV) systems have the potential to become competitive in the near future. They possess the highest efficiency of all existing PV technologies, and a smaller photovoltaic array also reduces the balance of system costs. Currently, CPV is not used in the PV roof top segment and far less common than conventional PV systems. [21]

Concentrating photovoltaic (CPV) modules work in much the same way as traditional PV modules, except that they use optics to concentrate the sun onto solar cells that do not cover the entire module area. This concentration factor - in Semprius' case over 1,100 times - dramatically reduces the amount of semiconductor needed $(<0.1$ percent $)$ and opens up the potential to cost-effectively use very highperformance multi-junction cells with efficiency levels greater than 41 percent. In order to work properly, however, CPV modules must accurately face the sun. Therefore, CPV modules are used in conjunction with high-performance trackers that intelligently and automatically follow the sun throughout the day. Other than this, CPV systems are built and operate much like traditional PV systems.

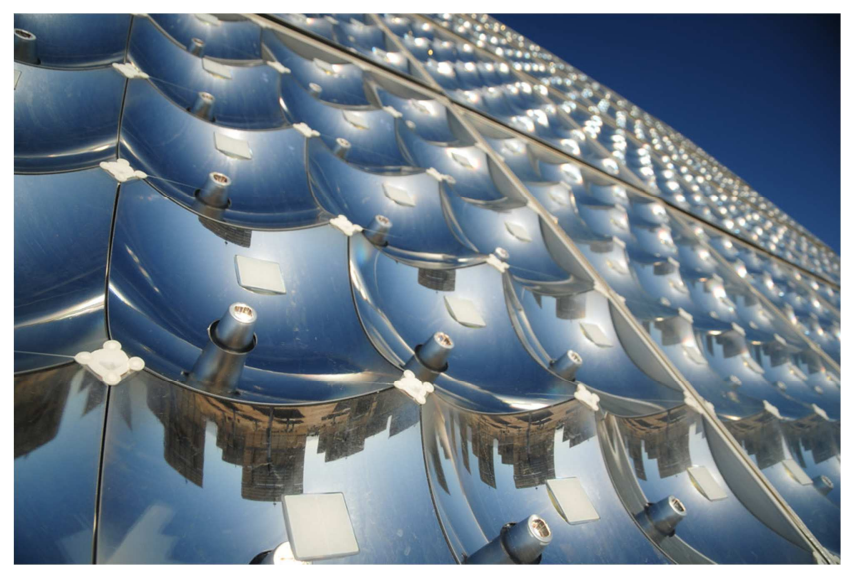

Fig. 6. Efficiency of $C P V$.

\subsection{Copper Indium Gallium Selenide Solar Cells (CI (G) S)}

One of the most interesting and controversial materials in solar is Copper-Indium-Gallium-Selenide, or CIGS for short. It was part of a solar thin-film-hype cycle where some CIGS companies such as Solyndra, NanoSolar and MiaSolé almost became household names. A copper indium gallium selenide solar cell (or CIGS cell, sometimes $\mathrm{CI}(\mathrm{G}) \mathrm{S}$ or CIS cell) is a thin film solar cell used to convert sunlight into electric power. They are manufactured by depositing a thin layer of copper, indium, gallium and selenide on glass or plastic backing, along with electrodes on the front and back to collect current. Because the material has a high absorption coefficient and strongly absorbs sunlight, a much thinner film is required than of other semiconductor materials.

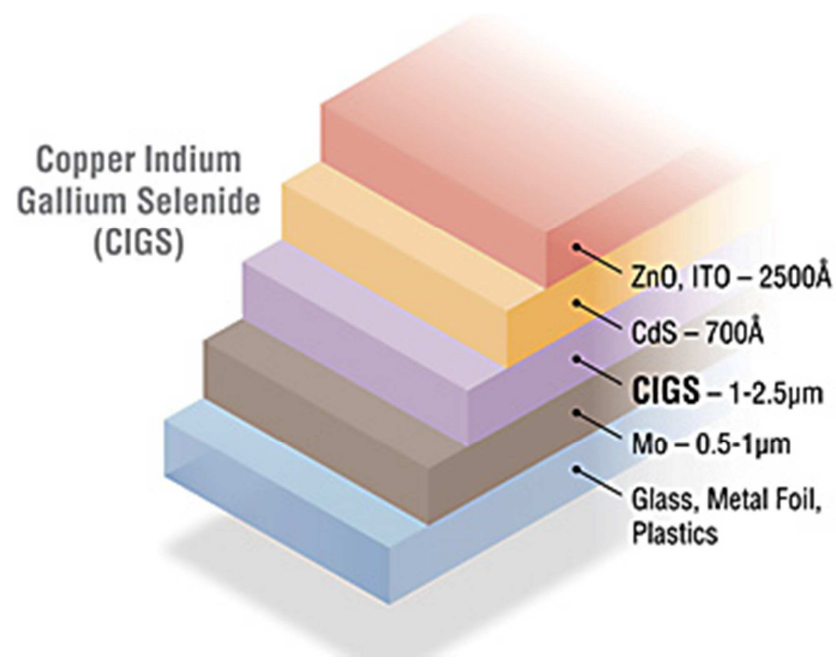

Fig. 7. Graphic showing the five layers that comprise CIGS solar cells.

CIGS is one of three mainstream thin-film PV technologies, the other two being cadmium telluride and amorphous silicon. Like these materials, CIGS layers are thin enough to be flexible, allowing them to be deposited on flexible substrates. However, as all of these technologies 
normally use high-temperature deposition techniques, the best performance normally comes from cells deposited on glass. Even then the performance is marginal compared to modern polysilicon-based panels. Advances in lowtemperature deposition of CIGS cells have erased much of this performance difference. It is best known as the material for CIGS solar cells a thin-film technology used in the photovoltaic industry.[22] In this role, CIGS has the advantage of being able to be deposited on flexible substrate materials, producing highly flexible, lightweight solar panels. Improvements in efficiency have made CIGS an established technology among alternative cell materials.

\subsection{Dye-Sensitized Solar Cell (DSSC)}

Dye Sensitized solar cells (DSSC), also sometimes referred to as dye sensitised cells (DSC), are a third generation photovoltaic (solar) cell that converts any visible light into electrical energy.This new class of advanced solar cell can be likened to artificial photosynthesis due to the way in which it mimics nature's absorption of light energy. Dye Sensitized solar cells (DSSC) were invented in 1991 by Professor Michael Graetzel and Dr Brian O'Regan at École Polytechnique Fédérale de Lausanne (EPFL), Switzerland and is often referred to as the Gräetzel cell, we call it G Cell. DSSC is a disruptive technology that can be used to produce electricity in a wide range of light conditions, indoors and outdoors, enabling the user to convert both artificial and natural light into energy to power a broad range of electronic devices. A dye-sensitized solar cell (DSSC, DSC or DYSC[23]) is a low-cost solar cell belonging to the group of thin film solar cells.[24] It is based on a semiconductor formed between a photo-sensitized anode and an electrolyte, a photo electrochemical system. The DSSC has a number of attractive features; it is simple to make using conventional roll-printing techniques, is semi-flexible and semitransparent which offers a variety of uses not applicable to glass-based systems, and most of the materials used are lowcost. In practice it has proven difficult to eliminate a number of expensive materials, notably platinum and ruthenium, and the liquid electrolyte presents a serious challenge to making a cell suitable for use in all weather. Although its conversion efficiency is less than the best thin-film cells, in theory its price/performance ratio should be good enough to allow them to compete with fossil fuel electrical generation by achieving grid parity. Commercial applications, which were held up due to chemical stability problems, [25] are forecast in the European Union Photovoltaic Roadmap to significantly contribute to renewable electricity generation by 2020 .
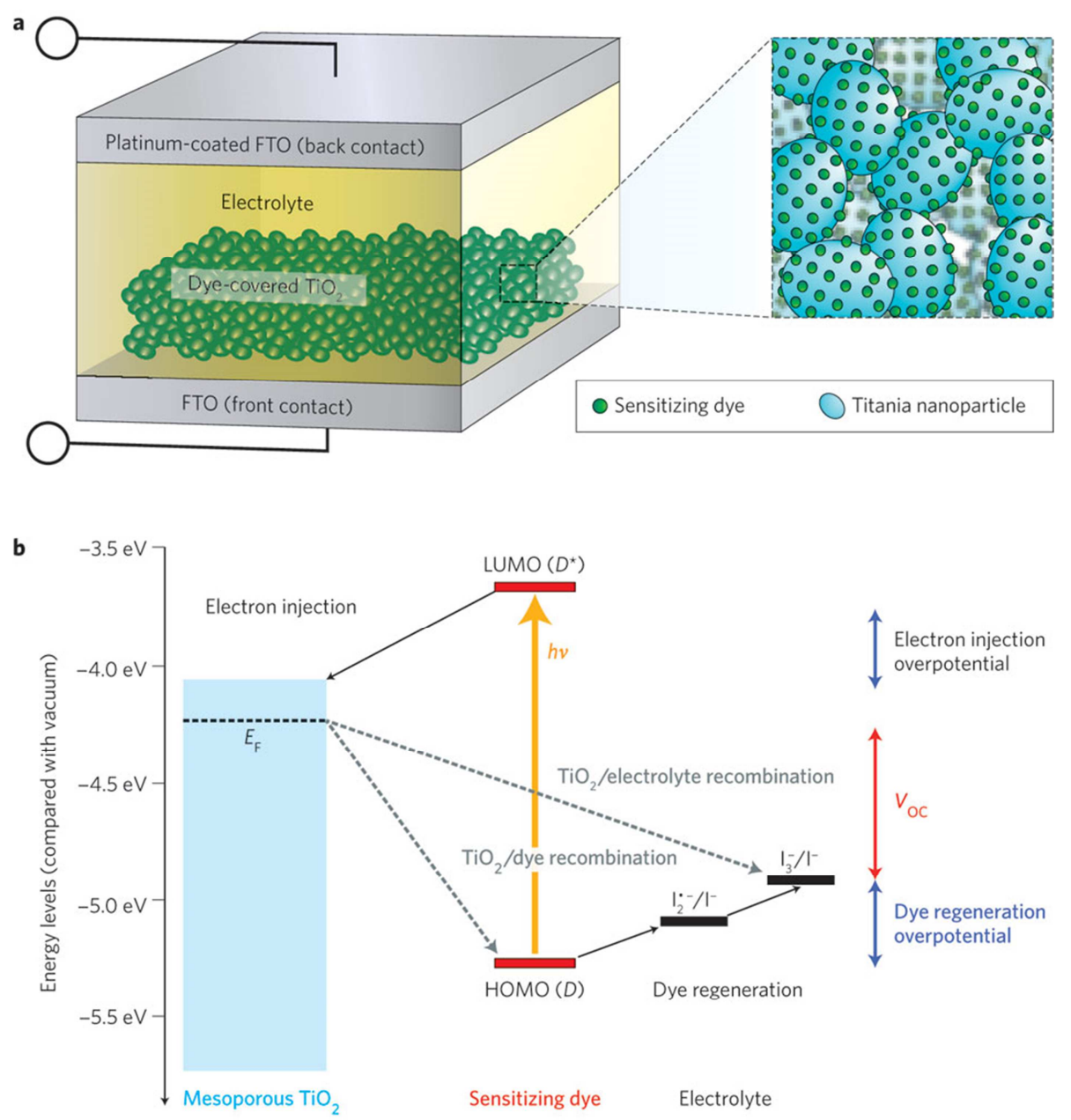

Fig. 8. Dye-sensitized solar cell device schematic and operation. 


\subsection{Gallium Arsenide Germanium Solar Cell (GaAs)}

Gallium arsenide is composed of 2 base elements; gallium and arsenic. When these two individual elements bind together, they form the aforementioned compound, which displays many interesting characteristics. Gallium arsenide is a semiconductor with a greater saturated electron velocity and electron mobility than that of siliconW. A semiconductor is a material that has electrical conductivity between an insulator and a conductor; it may vary its ability to conduct electricity when it is cool versus when it is hot. This makes it very useful in many applications. Another novel quality to gallium arsenide is that it has a direct band gap. This is a quality that denotes a compound that can emit light efficiently. Gallium arsenide (GaAs) is a compound of the elements gallium and arsenic. It is a III-V direct bandgap semiconductor with a zinc blende crystal structure. Gallium arsenide is used in the manufacture of devices such as microwave frequency integrated circuits, monolithic microwave integrated circuits, infrared light-emitting diodes, laser diodes, solar cells and optical windows.[26]

For example due to the fact that it has a greater electron mobility than silicon it can be used in different ways that silicon cannot. TransistorsW made of this material can run at frequencies over $250 \mathrm{GHz}$. These transistors produce less noise when operating at the same high frequencies as their silicon counterparts. Gallium arsenide also has a higher breakdown voltage. Breakdown voltage is the minimum (reverse) voltage applied that can cause to make a part of the component electrically conductive (or conduct in reverse).

Because of these factors, gallium arsenide has been a good candidate for many electrical applications ranging from the common to the extraordinary. Some of these include cellular telephones, satellites and satellite communication, micro and nano scale semiconductors, radar systems, and even nano based solar power. A solar cell is created to do one paramount task. That is the production of electricity through the absorption of photons. When light, in this case radiant energy from the sun, strikes the cell, a certain portion of it is absorbed within the semiconductor material. The semiconductor material in this case is that of the gallium arsenide. This means that the energy of the absorbed light is transferred to the semiconductor, in our case the gallium arsenide. The energy excites electrons, knocking them loose or otherwise removing them from their previous bound state. This allows them to flow freely. Solar and photo voltaic cells also have one or more electric fields that act as a mediator. This field forces electrons liberated by light absorption to flow in a certain direction. This flow of electrons, like many others, is a current. This current can be harnesssed by placing metal contacts on the top and bottom of the cell. With these newly placed contacts the current can be drawn off to power just about any external application. There are many ways to create a GaAs solar or photo voltaic cell. First the GaAs crystal must be created. Without this, the solar cell will not be able to function. In this section some methods to create
GaAs crystals will be discussed. Three effective means of growing crystals include: Molecular Beam Epitaxy, Metalorganic Vapour Phase Epitaxy, and Electrochemical Deposition (or Electroplating).

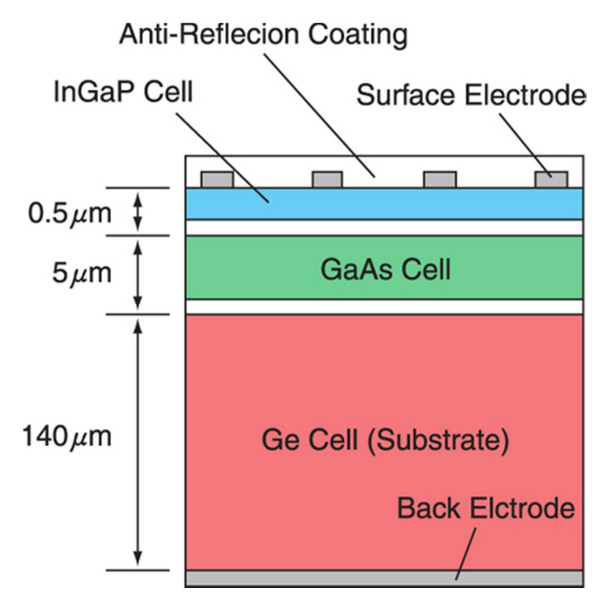

Fig. 9. Cross-sectional diagram of In $\mathrm{GaP} / \mathrm{GaAs} / \mathrm{Ge}$.

\subsection{Hybrid Solar Cell}

Hybrid solar cells combine advantages of both organic and inorganic semiconductors. Hybrid photovoltaics have organic materials that consist of conjugated polymers that absorb light as the donor and transport holes.[27] Inorganic materials in hybrid cells are used as the acceptor and electron transporter in the structure. The hybrid photovoltaic devices have a potential for not only low-cost by roll-to-roll processing but also for scalable solar power conversion.

In hybrid solar cells, an organic material is mixed with a high electron transport material to form the photoactive layer.[28] The two materials are assembled together in a heterojunction-type photoactive layer, which can have a greater power conversion efficiency than a single material.[29] One of the materials acts as the photon absorber and exciton donor. The other material facilitates exciton dissociation at the junction. Charge is transferred and then separated after an exiton created in the donor is delocalized on a donor-acceptor complex.[30] The energy required to separate the exciton is provided by the energy offset between the LUMOs or conduction bands of the donor and acceptor.[29] After dissociation, the carriers are transported to the respective electrodes through a percolation network. The average distance an exciton can diffuse through a material before annihilation by recombination is the exciton diffusion length. This is short in polymers, on the order of 510 nanometers.[31] The time scale for radiative and nonradiative decay is from 1 picosecond to 1 nanosecond.[32] Excitons generated within this length close to an acceptor would contribute to the photocurrent. To deal with the problem of the short exciton diffusion length, a bulk heterojunction structure is used rather than a phase-separated bilayer. Dispersing the particles throughout the polymer matrix creates a larger interfacial area for charge transfer to occur.[29] 


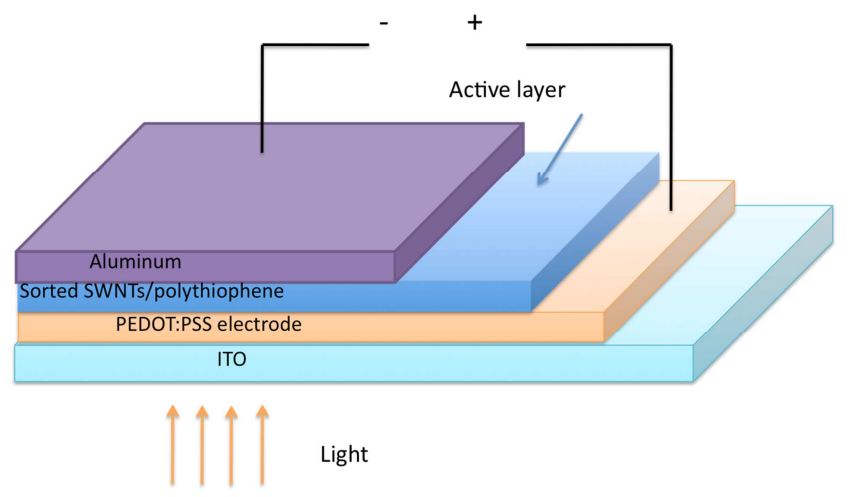

Fig. 10. Structure of carbon nanotubes based solar cells.

\subsection{Luminescent Solar Concentrator Cell (LSC)}

A luminescent solar concentrator (LSC) is a device that uses a thin sheet of material to trap solar radiation over a large area, before directing the energy (through luminescent emission) to cells mounted on the thin edges of the material layer. The thin sheet of material typically consists of a polymer (such as polymethylmethacrylate (PMMA)), doped with luminescent species such as organic dyes, quantum dots or rare earth complexes.[33]

The main motivation for implementing LSCs is to replace a large area of expensive solar cells in a standard flat-plate PV panel, with a cheaper alternative. Therefore there is both a reduction in both the cost of the module $(\mathfrak{f} / \mathrm{W})$ and the solar power produced $(£ / \mathrm{kWh})$. A key advantage of over typical concentrating systems is that LSCs can collect both direct and diffuse solar radiation. Therefore tracking of the sun is not required.[34]

The development of LSCs aims to create a working structure that performs close to the theoretical maximum efficiency. An ideal LSC would have the following properties: A broad absorption range to utalise the solar spectrum efficiently; $100 \%$ emission of light from the absorbing luminescent species; A large shift between the absorption and emission spectra to reduce absorption losses; and long term stability.[35]
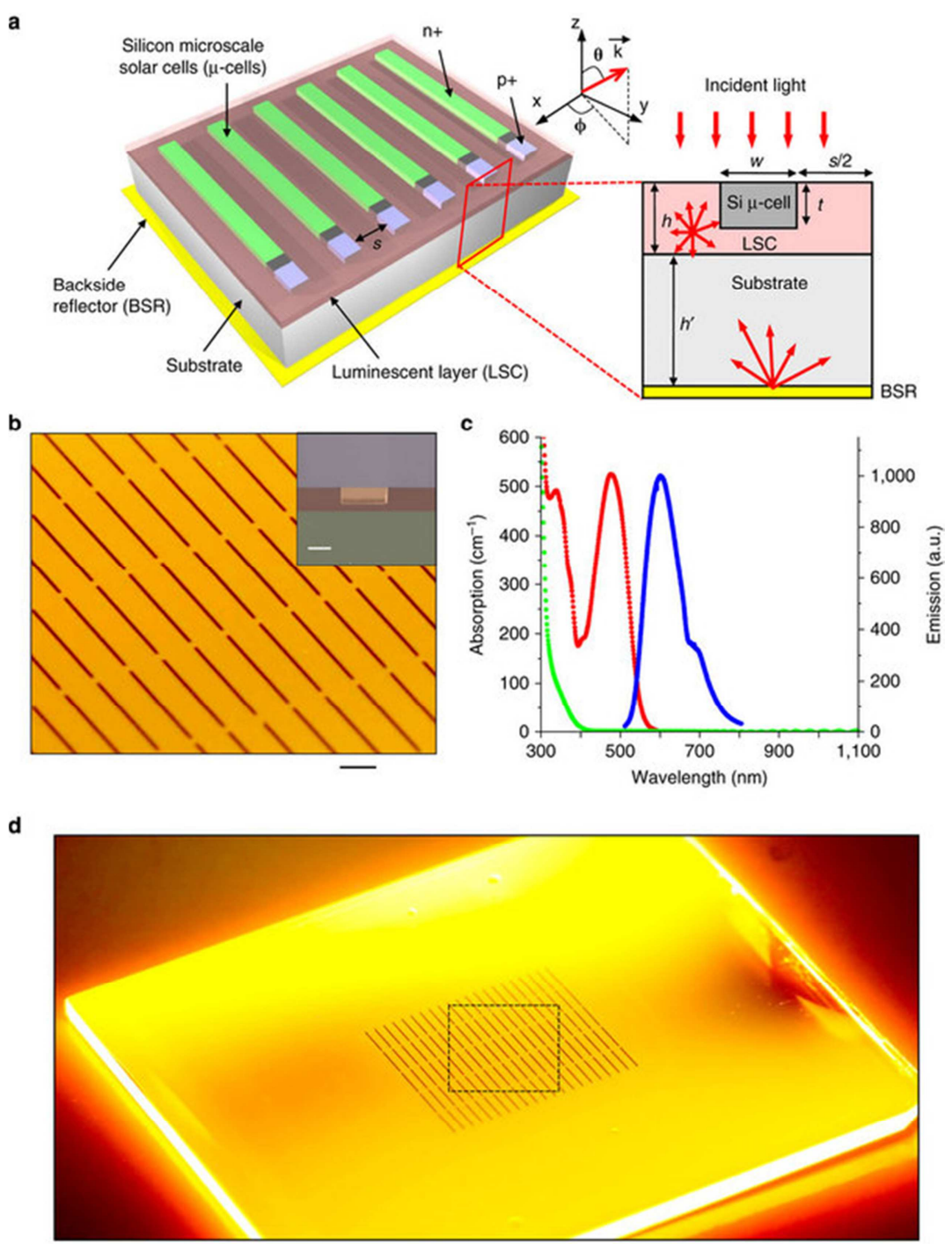

Fig. 11. A luminescent concentrator system with an array of surface-embedded monocrystalline silicon solar $\mu$-cells (a) Schematic illustration of a device, consisting of an array of solar microcells ( $\mu$-cells), a luminescent layer (LSC layer), a supporting, transparent substrate and a BSR. The inset on the right shows a cross sectional view, with key. 
Initial designs typically comprised parallel thin, flat layers of alternating luminescent and transparent materials, placed to gather incoming radiation on their (broader) faces and emit concentrated radiation around their (narrower) edges.[36][37] Commonly the device would direct the concentrated radiation onto solar cells to generate electric power.Other configurations (such as doped or coated optical fibers, or contoured stacks of alternating layers) may better fit particular applications.

The layers in the stack may be separate parallel plates or alternating strata in a solid structure. In principle, if the effective input area is sufficiently large relative to the effective output area, the output would be of correspondingly higher irradiance than the input, as measured in watts per square metre. The concentration factor is the ratio between output and input irradiance of the whole device. For example, imagine a square glass sheet (or stack) $200 \mathrm{~mm}$ on a side, 5 $\mathrm{mm}$ thick. Its input area (e.g. the surface of one single face of the sheet oriented toward the energy source) is 10 times greater than the output area (e.g. the surface of four open sides) - 40000 square $\mathrm{mm}(200 \times 200)$ as compared to 4000 square $\mathrm{mm}(200 \times 5 \times 4)$. To a first approximation, the concentration factor of such an LSC is proportional to the area of the input surfaces divided by the area of the edges multiplied by the efficiency of diversion of incoming light towards the output area. Suppose that the glass sheet could divert incoming light from the face towards the edges with an efficiency of $50 \%$. The hypothetical sheet of glass in our example would give an output irradiance of light 5 times greater than that of the incident light, producing a concentration factor of 5.Similarly, a graded refractive index optic fibre 1 square $\mathrm{mm}$ in cross section, and 1 metre long, with a luminescent coating might prove useful.

\subsection{Micromorph Cells (Tandem-Cell Using a-Si/Mc-Si)}

Micromorph cells are thin film solar cells based on a multijunction-architecture consisting of two solar cells that are stacked on top of each other. While the thin amorphous silicon top cell absorbs the blue light, the thicker microcrystalline silicon bottom cell absorbs the red and nearinfrared light, allowing this so-called tandem cell to cover a wider range of the solar spectrum. "Micromorph" tandem solar cells consisting of a microcrystalline silicon bottom cell and an amorphous silicon top cell are considered as one of the most promising new thin-film silicon solar-cell concepts. Their promise lies in the hope of simultaneously achieving high conversion efficiencies at relatively low manufacturing costs. Since the bandgaps of amorphous Silicon (1.7eV) and microcrystalline Silicon $(1.1 \mathrm{eV})$ are well suited for tandem solar cells, the Shockley-Queisser limit of this cell allows conversion efficiencies of over $30 \%$. In reality this limit can not be reached and typical stable efficiencies are about $9 \%$ (world record $11.7 \%$ ). That is well over the stable efficiencies of single junction thin film silicon solar cells which are around $6 \%$. One reason of the low costs of silicon thin film solar cells is its very low thickness $(2 \mu \mathrm{m})$ compared to silicon wafer $(200 \mu \mathrm{m})$. In the red and infrared wavelength range $2 \mu \mathrm{m}$ of silicon are not enough to absorb all light and therefore Light trapping is needed.

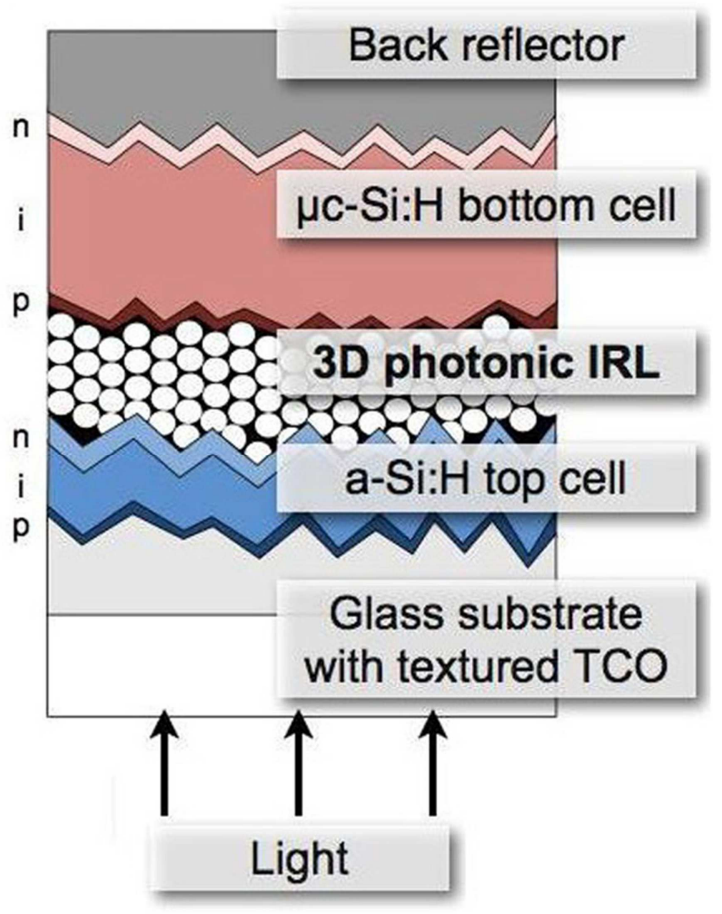

Fig. 12. Schematic structure of a micromorph silicon tandem cell with an integrated $3 D$ photonic crystal intermediate reflector. $\mu c-S i: H$ : Microcrystalline silicon.

\subsection{Monocrystalline Solar Cell (Mono-Si)}

Monocrystalline silicon (or "single-crystal silicon", "single-crystal Si", "mono c-Si", or just mono-Si) is the base material for silicon chips used in virtually all electronic equipment today. Mono-Si also serves as photovoltaic, lightabsorbing material in the manufacture of solar cells. It consists of silicon in which the crystal lattice of the entire solid is continuous, unbroken to its edges, and free of any grain boundaries. Mono-Si can be prepared intrinsic, consisting only of exceedingly pure silicon, or doped, containing very small quantities of other elements added to change its semiconducting properties. Most silicon monocrystals are grown by the Czochralski process into ingots of up to 2 meters in length and weighing several hundred kilogrammes. These cylinders are then sliced into thin wafers of a few hundred microns for further processing. Single-crystal silicon is perhaps the most important technological material of the last few decades - the "silicon era",[38] because its availability at an affordable cost has been essential for the development of the electronic devices on which the present day electronic and informatic revolution is based. Monocrystalline silicon differs from other allotropic forms, such as the non-crystalline amorphous silicon-used in thin-film solar cells, and polycrystalline silicon, that consists of small crystals, also known as crystallites. 


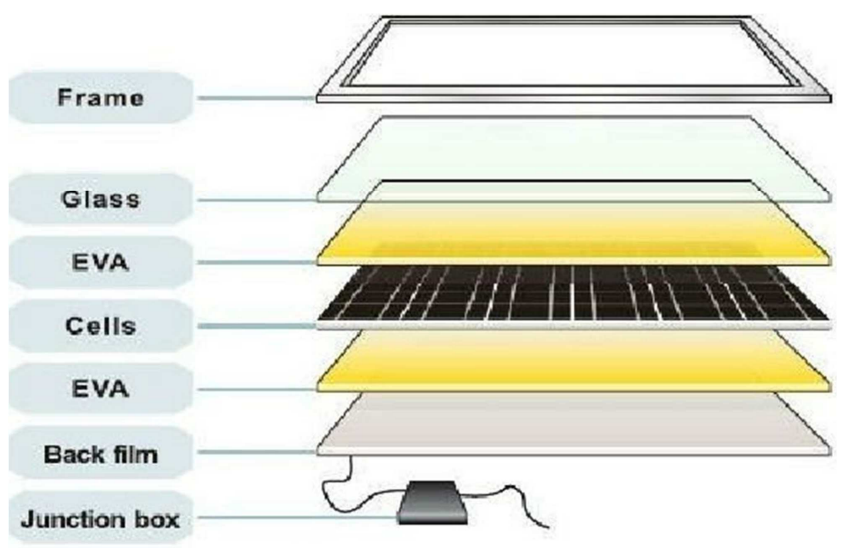

Fig. 13. Monocrystalline solar cell structure.

\subsection{Multijunction Solar Cell (MJ)}

Multi-junction (MJ) solar cells are solar cells with multiple $\mathrm{p}-\mathrm{n}$ junctions made of different semiconductor materials. Each material's p-n junction will produce electric current in response to different wavelengths of light. The use of multiple semiconducting materials allows the absorbance of a broader range of wavelengths, improving the cell's sunlight to electrical energy conversion efficiency. Traditional singlejunction cells have a maximum theoretical efficiency of $34 \%$. Theoretically, an infinite number of junctions would have a limiting efficiency of $86.8 \%$ under highly concentrated sunlight.[39]

Currently, the best lab examples of traditional crystalline silicon solar cells have efficiencies between $20 \%$ and $25 \%,[40]$ while lab examples of multi-junction cells have demonstrated performance over 43\%.[41] Commercial examples of tandem, two layer, cells are widely available at $30 \%$ under one-sun illumination,[42] and improve to around $40 \%$ under concentrated sunlight. However, this efficiency is gained at the cost of increased complexity and manufacturing price. To date, their higher price and higher price-toperformance ratio have limited their use to special roles, notably in aerospace where their high power-to-weight ratio is desirable. In terrestrial applications these solar cells have been suggested for use in concentrated photovoltaics (CPV), with numerous small test sites around the world. Tandem fabrication techniques have been used to improve the performance of existing designs. In particular, the technique can be applied to lower cost thin-film solar cells using amorphous silicon, as opposed to conventional crystalline silicon, to produce a cell with about $10 \%$ efficiency that is lightweight and flexible. This approach has been used by several commercial vendors, but these products are currently limited to certain niche roles, like roofing materials. Multi-junction (MJ) solar cells use multiple semiconductorW layers (subcells) to produce electricity at high operating efficiencies. Each layer has a unique band gapW designed to efficiently absorb a specific segment of the solar spectrumW. This has two important advantages over single-junction (SJ) devices: a wider range of absorption of incident photonsW as well as a more effective energy extraction from these photons. The lowest band gap of a MJ cell will be lower than that of a typical SJ band gap. Therefore, the MJ cell can absorb extra photons that possess less energy than the SJ band gap but greater than its own lowest band gap. The MJ cell will absorb the same photons more efficiently since having band gaps closer to the photon energy will reduce thermalization losses.

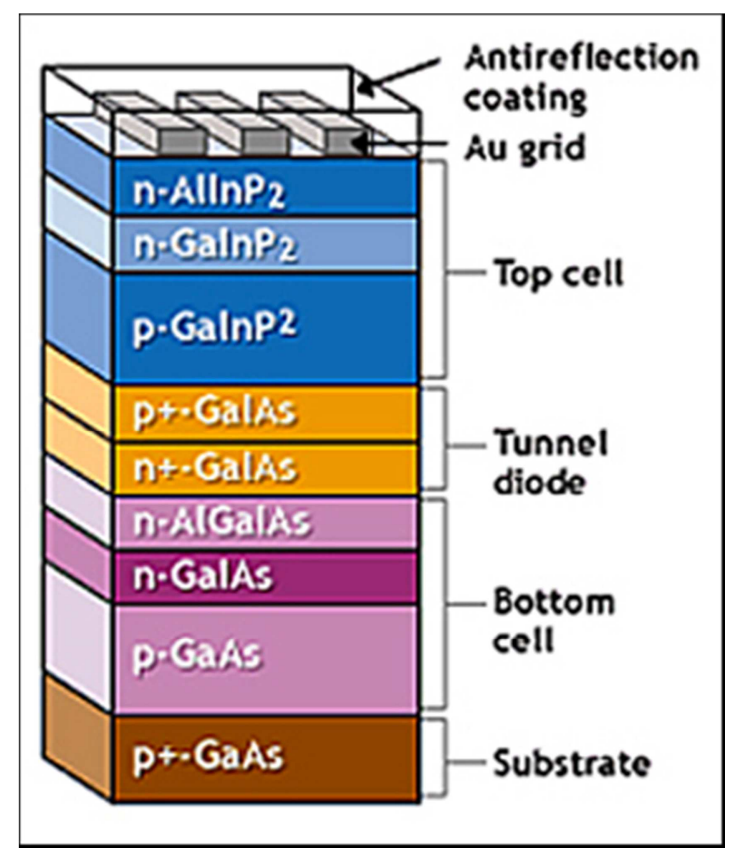

Fig. 14. Multi-junction Cell.

\subsection{Nanocrystal Solar Cell}

Nanocrystal solar cells are solar cells based on a substrate with a coating of nanocrystals. The nanocrystals are typically based on silicon, CdTe or CIGS and the substrates are generally silicon or various organic conductors. Quantum dot solar cells are a variant of this approach, but take advantage of quantum mechanical effects to extract further performance. Dye-sensitized solar cells are another related approach, but in this case the nano-structuring is part of the substrate.Previous fabrication methods relied on expensive molecular beam epitaxy processes, but colloidal synthesis allows for cheaper manufacture. A thin film of nanocrystals is obtained by a process known as "spin-coating". This involves placing an amount of the quantum dot solution onto a flat substrate, which is then rotated very quickly. The solution spreads out uniformly, and the substrate is spun until the required thickness is achieved. It is argued that many measurements of the efficiency of the nanocrystal solar cell are incorrect and that nanocrystal solar cells are not suitable for large scale manufacturing.[43]

Recent research has experimented with lead selenide (PbSe) semiconductor, as well as with cadmium telluride photovoltaics (CdTe), which has already been well established in the production of second-generation thin film solar cells. Other materials are being researched as well. What's more, solar cells made of silicon nanocrystals could 
prove to be cheap, giving them a significant advantage over other approaches to high-efficiency solar cells. For example, advanced "multijunction" cells have shown efficiencies of more than 40 percent. But these require complicated manufacturing processes that combine expensive semiconductors optimized for different parts of the solar spectrum. Silicon nanocrystals, in contrast, are relatively easy to make, even compared with the material in conventional solar cells, the best of which are made of very large, single crystals of silicon. Silicon nanocrystals also have marked advantages over the other nanocrystal materials that have shown the multielectron effect. Some of these materials contain toxic elements such as lead or cadmium, and others rely on elements such as indium that are in limited supply. But silicon is both safe and abundant. It's also well studied. Indeed, for many of the same reasons, silicon is by far the most common material in solar cells today, and it's attractive as the basis for broader deployment of photovoltaics in the future.

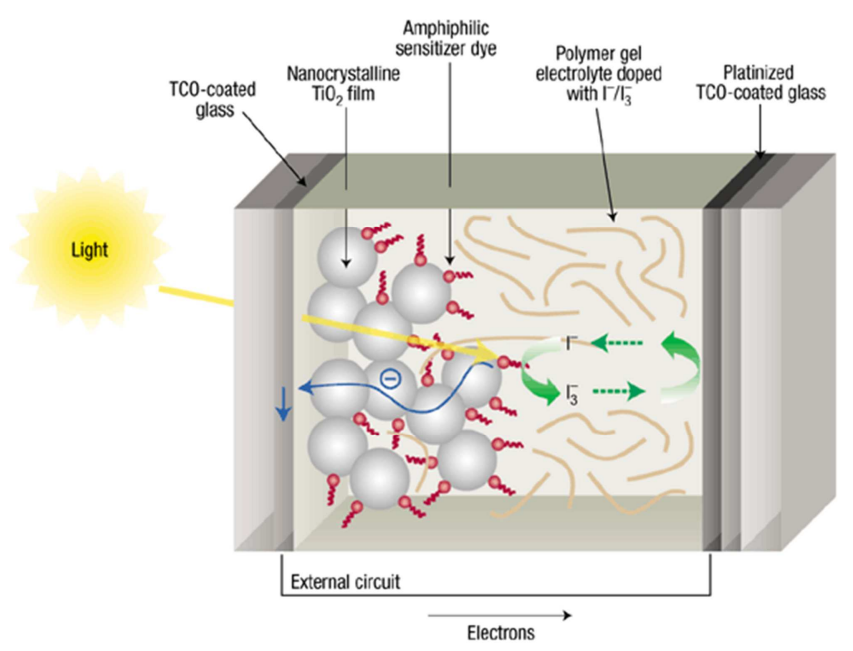

Fig. 15. The device made by Wang and colleagues 1 is based on a novel composite film comprising a mesoporous, nanocrystalline $\mathrm{TiO} 2$ film (the grey spheres) sensitized by an amphiphilic ruthenium dye (the red molecules), with polymer gel electrolyte (brown lines) interpenetrated into the film pores. This system is sandwiched between two transparent conducting oxide (TCO) electrodes. The function of the device is based on a photo-induced charge separation at the TiO2/dye/electrolyte interface. Light absorption by the sensitizer dye drives electron transfer from the excited state of the dye into the conduction band of the nanocrystalline TiO2. The dye subsequently returns to its ground state through electron donation from iodide ions in the gel electrolyte. Re-reduction of the iodine to iodide ions is achieved at the platinized counter electrode.

\subsection{Perovskite Solar Cell}

The name 'perovskite solar cell' is derived from the ABX3 crystal structure of the absorber materials, which is referred to as perovskite structure. The most commonly studied perovskite absorber is methylammonium lead trihalide ( $\mathrm{CH} 3 \mathrm{NH} 3 \mathrm{PbX} 3$, where $\mathrm{X}$ is a halogen ion such as $\mathrm{I}-, \mathrm{Br}-$, $\mathrm{Cl}-$ ), with an optical bandgap between $2.3 \mathrm{eV}$ and $1.6 \mathrm{eV}$ depending on halide content. Formamidinum lead trihalide (H2NCHNH2PbX3) has also shown promise, with bandgaps between $2.2 \mathrm{eV}$ and $1.5 \mathrm{eV}$. The minimum bandgap is closer to the optimal for a single-junction cell than methylammonium lead trihalide, so it should be capable of higher efficiencies.[44] A common concern is the inclusion of lead as component of the perovskite materials; solar cells based on tin-based perovskite absorbers such as $\mathrm{CH} 3 \mathrm{NH} 3 \mathrm{SnI} 3$ have also been reported with lower powerconversion efficiencies.[45][46][47]

Perovskite solar cells hold an advantage over traditional silicon solar cells in the simplicity of their processing. Traditional silicon cells require expensive, multistep processes requiring high temperatures (upwards of $1000{ }^{\circ} \mathrm{C}$ ) and vacuums in special clean room facilities to produce high purity silicon wafers.[48] These techniques are harder to scale up, while the organic-inorganic perovskite material can be manufactured with simpler wet chemistry and processing techniques in a traditional lab environment.[49] Most notably, methylammonium and formamidinium lead trihalides have been created using a variety of solvent techniques and vapor deposition techniques, both of which have the potential to be scaled up with relative feasibility.[50]

In solution processing, lead halide and methylammonium iodide can be dissolved in solvent and spin coated onto a substrate. Subsequent evaporation and convective selfassembly during spinning results in dense layers of well crystallized perovskite material, due to the strong ionic interactions within the material (The organic component also contributes to a lower crystallization temperature). However, simple spin-coating does not yield homogenous layers, instead requiring the addition of other chemicals such as GBL, DMSO, and toluene drips.[51] Simple solution processing results in the presence of voids, platelets, and other defects in the layer, which would hinder the efficiency of a solar cell. However, another technique using room temperature solvent-solvent extraction produces high-quality crystalline films with precise control over thickness down to 20 nanometers across areas several centimeters square without generating pinholes. In this method "perovskite precursors are dissolved in a solvent called NMP and coated onto a substrate. Then, instead of heating, the substrate is bathed in diethyl ether (DEE), a second solvent that selectively grabs the NMP solvent and whisks it away. What's left is an ultra-smooth film of perovskite crystals."[52]
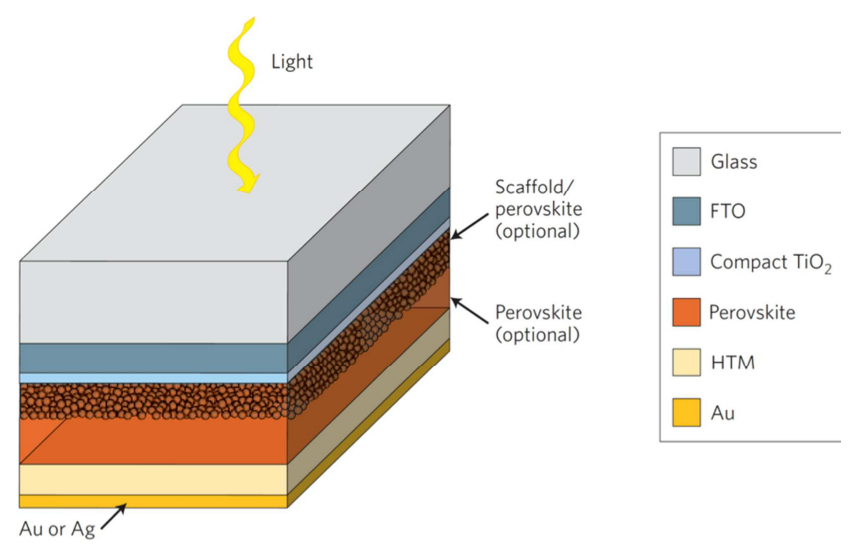

Fig. 16. Perovskite solar cell structure. 
In vapor assisted techniques, spin coated or exfoliated lead halide is annealed in the presence of methylammonium iodide vapor at a temperature of around $150{ }^{\circ} \mathrm{C}$. This technique holds an advantage over solution processing, as it open up the possibility for multi-stacked thin films over larger areas.[53] This could be applicable for the production of multi-junction cells. Additionally, vapor deposited techniques result in less thickness variation than simple solution processed layers. However, both techniques can result in planar thin film layers or for use in mesoscopic designs, such as coatings on a metal oxide scaffold. Such a design is common for current perovskite or dye-sensitized solar cells. Both processes hold promise in terms of scalability. Process cost and complexity is significantly less than that of silicon solar cells. Vapor deposition or vapor assisted techniques reduce the need for use of further solvents, which reduces the risk of solvent remnants. Solution processing is cheaper. Current issues with perovskite solar cells revolve around stability, as the material is observed to degrade in standard environmental conditions, suffering drops in efficiency Broadly speaking, solar cells can be divided into two distinct groups - those based on inorganic photovoltaic materials, such as silicon or cadmium telluride, and those based on specific organic compounds, such as PCDTBT. Both have their own respective advantages and disadvantages. The inorganic materials are already industrially well-established, capable of converting light to electricity at greater than $20 \%$ efficiency and create solar panels with more than 25-year lifespans. The downside is that the raw materials required, particularly with silicon, can be expensive. Organic solar cells are based on potentially low-cost materials and can even be manufactured from a liquid solution, which makes them very fast and cheap to produce. However, even on a laboratory-scale, organic solar cells struggle to achieve efficiencies of more than $10 \%$. Even more crucially, the organic compounds gradually decompose under light, often reducing panel lifetime to the order of months or weeks rather than years. Consequently these organic materials have rarely been used to produce solar panels, as no one likes the idea of having to climb on their roof to replace them every six months. Ideally we want a solar cell with the performance and long term stability of inorganic materials with the ultra-low cost of organic materials. In the past few years solar energy research has witnessed the emergence of a remarkable new class of materials known as perovskites. This is a hybrid organicinorganic material, essentially an organic compound with an inorganic element attached. Perovskite refers to the specific type of crystal structure, which occurs naturally in certain minerals. These hybrid compounds have this crystal structure but are also a complex combination of organic ammonia and methyl groups with inorganic lead iodide or lead chloride molecules attached. The reason for the excitement surrounding these materials is the frankly staggering rate at which they have developed. Previously whenever a new material was discovered it had taken some 10-20 years of research to reach an efficiency rate of even $10 \%$. Perovskite solar cells only emerged in 2012, but have already clocked up conversions of more than $19 \%$ efficiency. This blistering rate of development is unprecedented in solar research. As a hybrid material, as well as boasting good efficiencies as with inorganic materials, perovskites can also take advantage of organic solar materials' capacity to be applied as a liquid solution. This is what Professor David Lidzey's group at the University of Sheffield has taken advantage of, spraying the perovskite as a liquid coating onto a substrate material. This allows solar cells to be manufactured at high volumes and low cost. There are some questions regarding the potential environmental impact of the lead content of the material (although work is ongoing to remove the requirement for lead) and how easily production can be up-scaled to a useful commercial size. As with organic solar cells, their long term stability is also highly questionable and they are particularly sensitive to moisture - a few drops of water can completely destroy the material. So building a perovskite solar panel module capable of surviving for decades outdoors is most likely still some way off - in fact there's no guarantee it's even possible. But what is for certain is that the potential of perovskite solar cells is staggering, and if the material's promise can be realised it could completely revolutionise the capabilities of solar energy.

\subsection{Photoelectrochemical Cell (PEC)}

Photo electrochemical (PEC) cells offer a promising method of hydrogen production driven directly by solar energy, however materials limitations have significantly hindered their efficiency. The objective of our research is to improve the efficiencies of PEC cells by identifying and engineering corrosion-resistant semiconductors that exhibit the optimal conduction and valence band edge alignment for PEC applications. PEC cells utilize light energy (photons) to perform a chemical reaction, in this case the splitting of water into hydrogen (H2) and oxygen (O2) gases. They consist of an anode and a cathode immersed in an electrolyte and connected in an external circuit. Typically, the anode or the cathode consists of a semiconductor that absorbs sunlight, and the other electrode is typically a metal. Photons with energies greater than the semiconductor band gap can be absorbed by the semiconductor, creating electron-hole pairs which are split by the electric field in the space-charge region between the semiconductor and the electrolyte. The electric field reflects the band bending of the conduction and valence band edges at the semiconductor surface and is necessary to supply the free carriers to the appropriate electrode.

The major advantages of photoelectrochemical devices are the great ease with which the semiconductor-electrolyte junction is formed (the semiconductor is simply immersed into the electrolyte) and that the fact that thin, polycrystalline, semiconductor films can be used without serious loss of conversion efficiency compared to single crystal semiconductors. Although significant advances have been made, both in the basic understanding of photoelectrochemical devices and in the development of systems with good conversion efficiency and stability, much 
additional research and development must be done before photoelectrochemical systems can be seriously considered for practical solar energy conversion schemes. PECs offer several potential advantages over solid-state junction devices, including easier fabrication, flexibility, and the ability to directly produce hydrogen [54]. Although high-efficiency PECs have been developed [55][56], their commercialization has been slowed by the inability to identify electrode materials that are cheap, efficient, and stable.

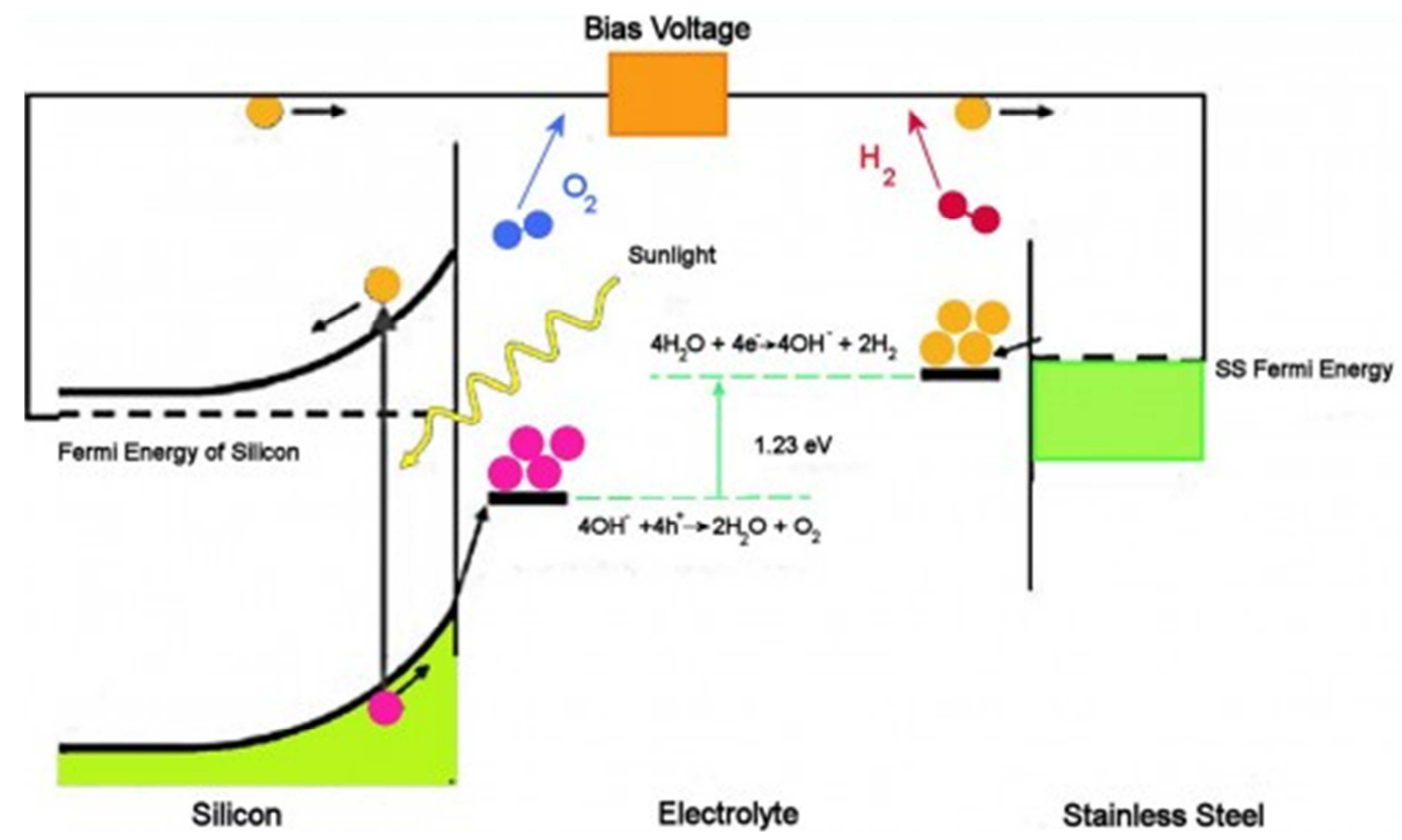

Fig. 17. The figure above illustrates how a PEC cell operates. Briefly, incoming sunlight excites free electrons near the surface of the silicon electrode.

\subsection{Polymer Solar Cell}

The material used to absorb the solar light in organic solar cells, is an organic material such as a conjugated polymer. The basic principle behind both the polymer solar cell and other forms of solar cells, however, is the same, namely the transformation of the energy in the form of electromagnetic radiation (light) into electrical energy (a current and a voltage), i.e. a physical phenomenon called the photovoltaic effect. This energy conversion is possible with the use of semiconductors. Semiconductors are a group of materials which are in-between an insulator and a conductor. Silicon is a classic example of a semiconductor and is also the material that is currently used in most solar cells, i.e. the first generation solar cells. The fact that polymers can behave as semiconductors is a discovery which Alan J. Heeger, Alan MacDiarmid and Hideki Shirakawa received the Nobel Prize in Chemistry for in the year 2000. This discovery of conjugated polymers being able to transfer electrons upon doping with iodine made it possible to prepare solar cells from polymers and thereby a new research area was born.Polymer solar cells have for a long time lagged behind traditional solar cells on both performance and stability. However, they have always had a potential advantage; that is their ability to be produced from solution. This means that they can be printed or coated, instead of using expensive vacuum deposition as for the first generation silicon solar cells. Today, performances of $10 \%$ have been demonstrated for polymer solar cells.[57] The lifetime has also improved considerably and plastic solar cells with a shelf life of several years have been demonstrated.[58][59] In addition, large scale production of polymer solar cells is today to some extent a reality, as demonstrated by for example the freeOPV initiative.[60] In this section you can learn why we think polymer solar cells are the future, how they work, and how they are made. A polymer solar cell is a type of flexible solar cell made with polymers, large molecules with repeating structural units, that produce electricity from sunlight by the photovoltaic effect. Polymer solar cells include organic solar cells (also called "plastic solar cells"). They are one type of thin film solar cell, others include the more stable amorphous silicon solar cell. Most commercial solar cells are made from a refined, highly purified silicon crystal, similar to the material used in the manufacture of integrated circuits and computer chips (wafer silicon). The high cost of these silicon solar cells and their complex production process generated interest in alternative technologies.Compared to silicon-based devices, polymer solar cells are lightweight (which is important for small autonomous sensors), potentially disposable and inexpensive to fabricate (sometimes using printed electronics), flexible, customizable on the molecular level and potentially have less adverse environmental impact. Polymer solar cells also 
have the potential to exhibit transparency, suggesting applications in windows, walls, flexible electronics, etc.
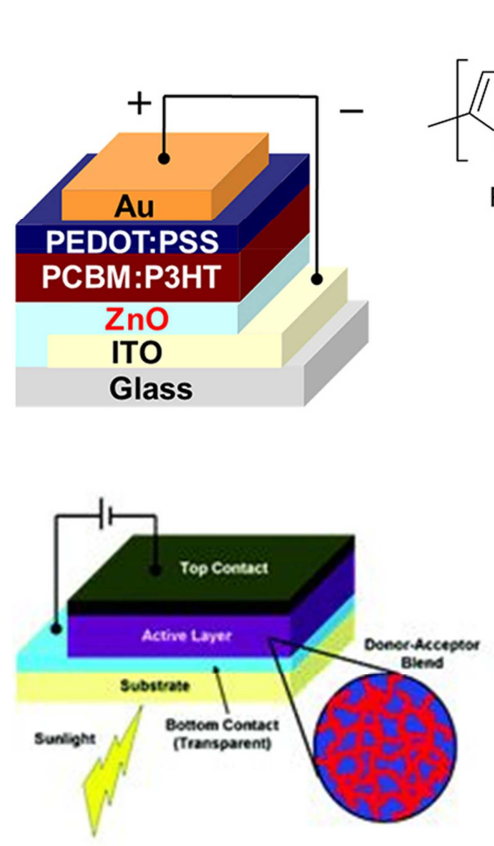
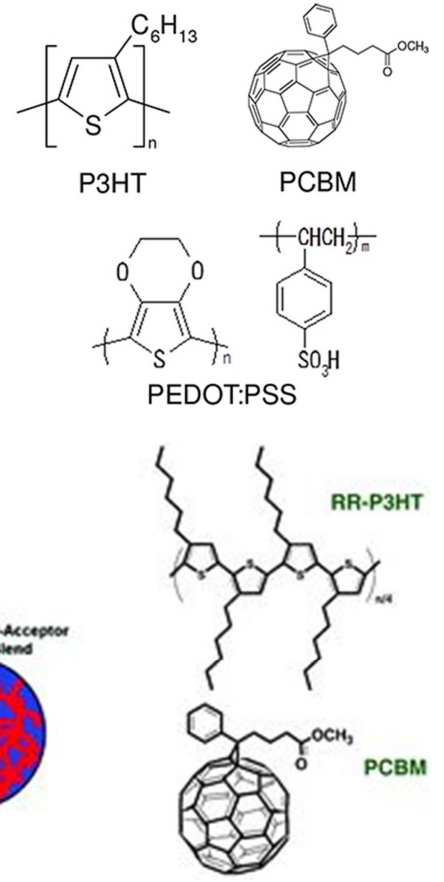

Fig. 18. Currently, polymer solar cells are far behind the conventional silicon solar cells. However, as thrusts for green energy continue, the relative low cost of the polymer solar cells could play a big role, and the huge jumps these cells are making in terms of efficiency only makes things better for them. A recently developed nano-patterned array production technique showed researchers a seven-fold increase in efficiency as compared to the conventional sandwich-style construction.

Listing the advantages of polymer solar cells reveals a very enticing selling point; however, polymer solar cells have a number of drawbacks. Firstly, while inorganic silicon-based solar cells may last on the order of 25 years; polymer based devices struggle to last a year. Efficiency has long remained the other major drawback of the technology. With polymer solar cell the efficiency is still behind more traditional technologies, but recent records exceeding $10 \%$ have been reported.[61] For polymer solar cells to mature to the market, the strong points of the technology will have to match the weak points. However, it is still vital to optimize the weak points. Professor Fredrik C. Krebs have defined the unification challenge of polymer solar cells by stating that three issues share the same importance.[62][63] These three issues were defined as; process, stability, and efficiency. The concept is very similar to the critical triangle for photovoltaics as presented by Professor Christoph J. Brabec, however substituting processability for cost.[64] While no issue can be argued more important than another, the efficiency of solar cells have long been given special attention. As an area of focus, the power conversion efficiency is important in order to compete with the more mature silicon technology and to justify research in the field of polymer solar cells. As long as focus of research is not on all of the areas, progress towards application of the technology will remain slow. Within recent years the number of reports on both processability and stability has increased significantly. Roll-to-roll production is becoming an established technique for producing polymer solar cells. And more and more work has been published on the stability and degradation including guiding standards for testing OPV devices with respect to stability and operational lifetime.

\subsection{Polycrystalline Solar Cell (Multi-Si)}

Polycrystalline silicon, also called polysilicon or poly-Si, is a high purity, polycrystalline form of silicon, used as a raw material by the solar photovoltaic and electronics industry.

Polysilicon is produced from metallurgical grade silicon by a chemical purification process, called Siemens process. This process involves distillation of volatile silicon compounds, and their decomposition into silicon at high temperatures. An emerging, alternative process of refinement uses a fluidized bed reactor. The photovoltaic industry also produces upgraded metallurgical-grade silicon (UMG-Si), using metallurgical instead of chemical purification processes. When produced for the electronics industry, polysilicon contains impurity levels of less than one part per billion ( $\mathrm{ppb}$ ), while polycrystalline solar grade silicon (SoG$\mathrm{Si}$ ) is generally less pure. A few companies from China, Germany, Japan, Korea and the United States, such as GCLPoly, Wacker Chemie, OCI, and Hemlock Semiconductor, as well as the Norwegian headquartered REC, accounted for most of the worldwide production of about 230,000 tonnes in 2013.[65]

The polysilicon feedstock - large rods, usually broken into chunks of specific sizes and packaged in clean rooms before shipment - is directly cast into multicrystalline ingots or submitted to a recrystallization process to grow single crystall boules. The products are then sliced into thin silicon wafers and used for the production of solar cells, integrated circuits and other semiconductor devices.Polysilicon consists of small crystals, also known as crystallites, giving the material its typical metal flake effect. While polysilicon and multisilicon are often used as synonyms, multicrystalline usually refers to crystalls larger than $1 \mathrm{~mm}$. Multicrystalline solar cells are the most common type of solar cells in the fast-growing PV market and consume most of the worldwide produced polysilicon. About 5 tons of polysilicon is required to manufacture 1 megawatt (MW) of conventional solar modules.[66] Polysilicon is distinct from monocrystalline silicon and amorphous silicon.

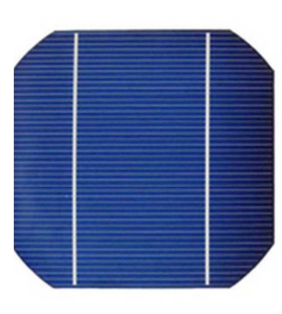

Mono

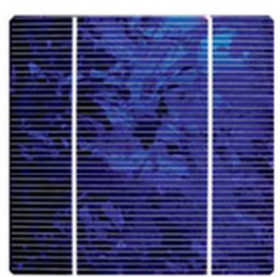

Poly

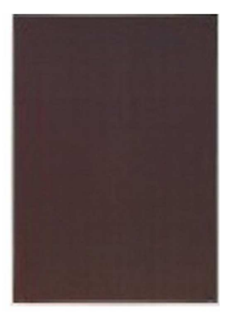

Thin Film
Fig. 19. Solar Panels. 


\subsection{Quantum Dot Solar Cell}

A quantum dot solar cell is a solar cell design that uses quantum dots as the absorbing photovoltaic material. It attempts to replace bulk materials such as silicon, copper indium gallium selenide (CIGS) or CdTe. Quantum dots have bandgaps that are tunable across a wide range of energy levels by changing the dots' size. In bulk materials the bandgap is fixed by the choice of material(s). This property makes quantum dots attractive for multi-junction solar cells, where a variety of materials are used to improve efficiency by harvesting multiple portions of the solar spectrum. Quantum dots are semiconducting particles that have been reduced below the size of the Exciton Bohr radius and due to quantum mechanics considerations, the electron energies that can exist within them become finite, much alike energies in an atom. Quantum dots have been referred to as "artificial atoms". These energy levels are tuneable by changing their size, which in turn defines the bandgap. The dots can be grown over a range of sizes, allowing them to express a variety of bandgaps without changing the underlying material or construction techniques.[67] In typical wet chemistry preparations, the tuning is accomplished by varying the synthesis duration or temperature.

The ability to tune the bandgap makes quantum dots desirable for solar cells. Single junction implementations using lead sulfide (PbS) CQDs have bandgaps that can be tuned into the far infrared, frequencies that are typically difficult to achieve with traditional. Half of the solar energy reaching the Earth is in the infrared, most in the near infrared region. A quantum dot solar cell makes infrared energy as accessible as any other.[68]

Moreover, CQDs offer easy synthesis and preparation. While suspended in a colloidal liquid form they can be easily handled throughout production, with a fumehood as the most complex equipment needed. CQDs are typically synthesized in small batches, but can be mass-produced. The dots can be distributed on a substrate by spin coating, either by hand or in an automated process. Large-scale production could use spray-on or roll-printing systems, dramatically reducing module construction costs. Early examples used costly molecular beam epitaxy processes, but less expensive fabrication methods were later developed. These use wet chemistry (colloidal quantum dots - CQDs) and subsequent solution processing. Concentrated nanoparticle solutions are stabilized by long hydrocarbon ligands that keep the nanocrystals suspended in solution. To create a solid, these solutions are cast down[clarification needed] and the long stabilizing ligands are replaced with short-chain crosslinkers. Chemically engineering the nanocrystal surface can better passivate the nanocrystals and reduce detrimental trap states that would curtail device performance by means of carrier recombination. This approach produces an efficiency of 7.0\%.[69] In 2014 the use of iodide as a ligand that does not bond to oxygen was introduced. This maintains stable $\mathrm{n}$ - and p-type layers, boosting the absorption efficiency, which produced power conversion efficiency up to 8\%.[70] Solidstate solar cell
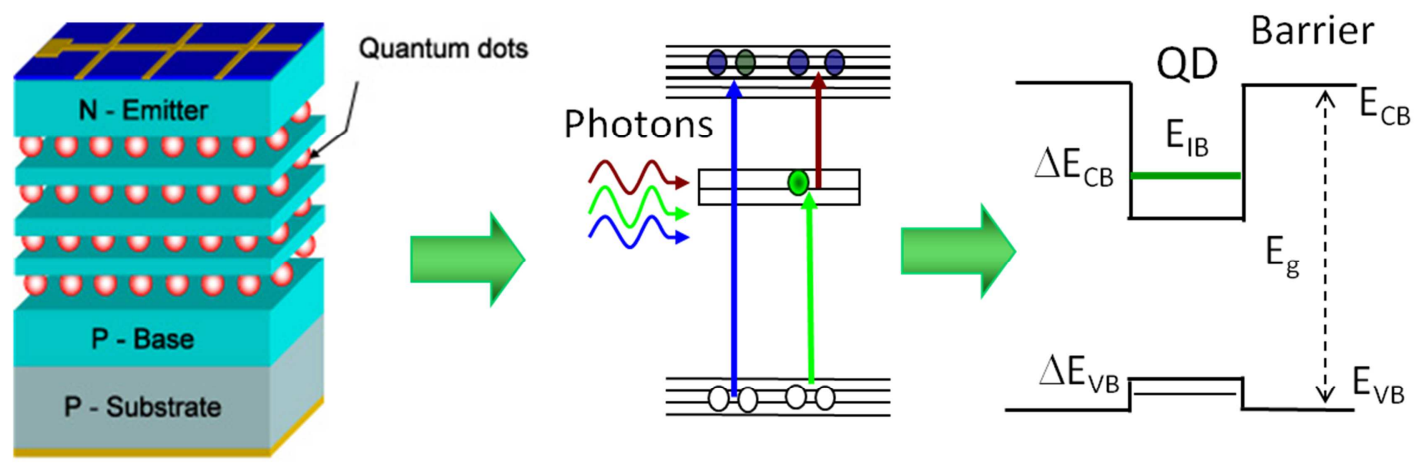

Schematic of operating principle and energy band diagram of proposed III-(As, SB) solar cell

Fig. 20. Quantum dot solar cell.

\subsection{Thin Film Solar Cell (TFSC)}

A thin-film solar cell (TFSC), also called a thin-film photovoltaic cell (TFPV), is a second generation solar cell that is made by depositing one or more thin layers, or thin film (TF) of photovoltaic material on a substrate, such as glass, plastic or metal. Thin-film solar cells are commercially used in several technologies, including cadmium telluride (CdTe), copper indium gallium diselenide (CIGS), and amorphous and other thin-film silicon (a-Si, TF-Si).

Film thickness varies from a few nanometers (nm) to tens of micrometers $(\mu \mathrm{m})$, much thinner than thin-film's rival technology, the conventional, first-generation crystalline silicon solar cell (c-Si), that uses silicon wafers of up to 200 $\mu \mathrm{m}$. This allows thin film cells to be flexible, lower in weight, and have less drag. It is used in building integrated photovoltaics and as semi-transparent, photovoltaic glazing material that can be laminated onto windows. Other commercial applications use rigid thin film solar panels (sandwiched between two panes of glass) in some of the world's largest photovoltaic power stations.

Thin-film has always been cheaper but less efficient than conventional c-Si technology. However, they significantly improved over the years, and lab cell efficiency for CdTe and CIGS are now beyond 21 percent, outperforming multicrystalline silicon, the dominant material currently used 
in most solar PV systems.[71]:23,24 Despite these enhancements, market-share of thin-film never reached more than 20 percent in the last two decades and has been declining in recent years to about 9 percent of worldwide photovoltaic production in 2013.[71] Other thin-film technologies, that are still in an early stage of ongoing research or with limited commercial availability, are often classified as emerging or third generation photovoltaic cells and include, organic, dye-sensitized, and polymer solar cells, as well as quantum dot, copper zinc tin sulfide, nanocrystal, micromorph and perovskite solar cells.

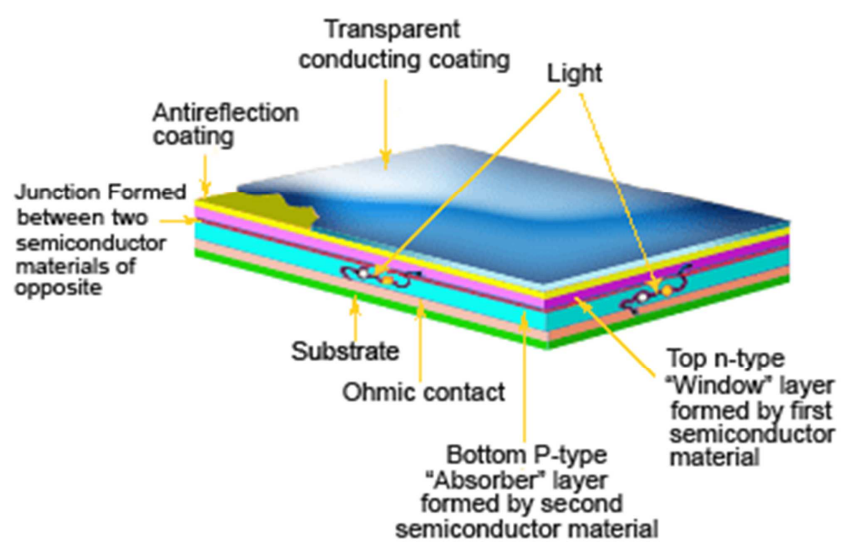

Fig. 21. Structure of thin film solar cells.

\subsection{Black Silicon Solar Cells}

Black silicon solar cells are similar to crystalline silicon solar cells. Really similar. The difference is that black silicon solar cells are treated so that they appear to be black on the surface. Why is that a big deal? Think of wearing a black Tshirt on a hot summer day. The black color tends to absorb more sunlight, which translates to an uncomfortable summer afternoon for you, but more energy gathered for a solar cell. It's an attractive option for areas that don't get as much sunlight but still want to make good use of the light they do receive. Until now, turning silicon cells black tended to undercut their efficiency at turning sunlight into power, however. Black silicon can be manufactured simply by adding a dense network of nanoscale needles on top of a standard piece of silicon. Modifying the material in this way makes it a lot less reflective, allowing solar cells that use it to trap light even when it's coming from very low angles. This could be a good way to increase the yield of solar cells throughout the day, particularly in countries at higher latitudes. On top of this, black silicon cells could also be cheaper, as they don't need the antireflection coatings used by many other types of solar cells. The main issue that has stifled the progress of black silicon cells is something known as carrier recombination. When a photon hits a silicon atom inside a solar cell, the excess energy frees up an electron that is later used to generate electricity. Using Black Silicon as substrate allows fabricating Black Silicon solar cells. For the Black Silicon laser process, the laser pulse shape was altered by optical laser pulse shaping equipment. With these shaped laser pulses, less crystal damage is achieved in the silicon during the laser silicon interaction. This facilitates minimizing surface recombination losses. The laser structuring itself simultaneously forms the front side texture and the emitter in one single process step, while it also modifies the raw silicon material enabling it to absorb the IR portion of the sun spectra. Using Black Silicon as substrate allows to fabricate Black Silicon solar cells. For the Black Silicon laser process, the laser pulse shape was altered by optical laser pulse shaping equipment. With these shaped laser pulses, less crystal damage is achieved in the silicon during the laser silicon interaction. This facilitates minimizing surface recombination losses. The laser structuring itself simultaneously forms the front side texture and the emitter in one single process step, while it also modifies the raw silicon material enabling it to absorb the IR portion of the sun spectra. After laser structuring, evaporated front contacts and a screen printed rear contact are deposited. An edge isolation is not necessary, as the emitter is only formed on the front side. The process flow of the femtosecond laser processed Black Silicon solar cell is displayed. As the front side texturing and the emitter formation take place during the laser process, the total number of process steps is significantly reduced and can potentially cut production costs. The finished solar cells display high short circuit current densities in the range of $38 \mathrm{~mA} / \mathrm{cm} 2<\mathrm{Jsc}<42 \mathrm{~mA} / \mathrm{cm} 2$ due to their increased absorption of IR light. We achieve an efficiency of $4.5 \%$ with no passivation layers applied. The previously reported record efficiency realized by Harvard University was $2.2 \%$ for a laser processed Black Silicon solar cell.

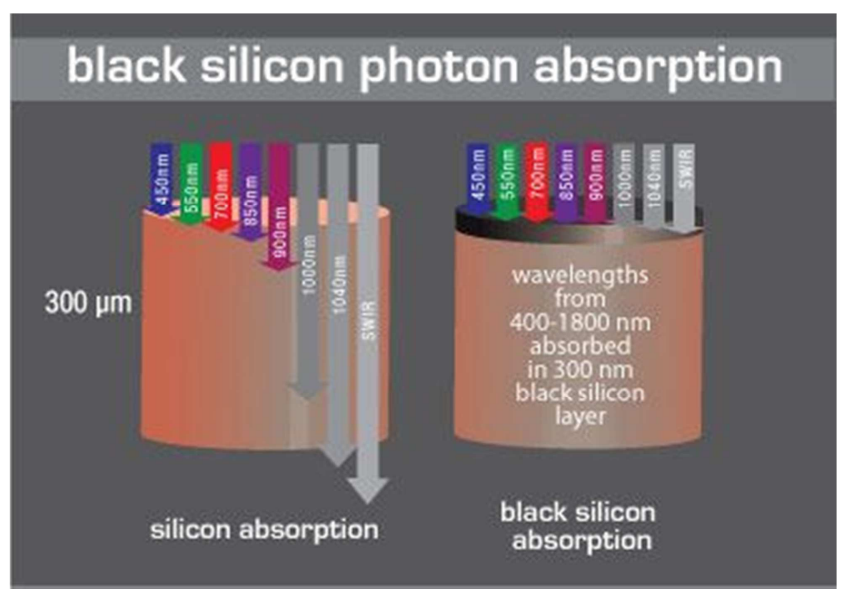

Fig. 22. The Future of Black Silicon.

Occasionally, though, the electron simply recombines with a silicon atom, effectively wasting the energy provided by the photon. Recombination is proportional to the surface area of the silicon, and the needles on the surface of dark silicon raise surface area so much that about half of the freed electrons are "lost" in this way. Now, a team of researchers led by assistant professor Hele Savin has managed to get around the issue, and in so doing, it has increased the record efficiency of black silicon cells by almost four percentage points, up to 22.1 percent. Their real-life performance is 
however better than that as the researchers were also able to show that, thanks to their ability to accept sunlight from lower angles, black silicon cells can gather three percent more energy than a cell with the same nominal efficiency over the course of the entire day.Savin and colleagues put recombination in check by applying a thin aluminum film, acting like a chemical and electronic shield, on top of the nanostructures. They also integrated all the metal contacts on the back side of the cell, for added absorption.

These two changes meant that only four percent of the freed up electrons recombined, as opposed to the previous 50 percent. The new cell design is however likely not pushing this technology to its limit just yet, since it made use of ptype silicon rather than the more durable n-type silicon. According to the scientists, a better choice of materials or a better cell structure would push efficiencies even further. The near-term goal for the researchers is to apply their technology to other cell structures, thin and multi-crystalline cells in particular - but also, Savin tells us, other devices like screens and photodetectors.

\section{Result and Discussion}

Solar energy which is a combination of light and heat is produced by sun. This energy moves from sun and reaches the earth where human collects it through solar collectors and convert it into any desirable form of energy. According to an assumption this renewable source of energy is powerful enough to replace the need of electricity that we get from 650 barrels of oil per year.

Some of Applications of solar enery

1. Power plants: In conventional power plants nonrenewable energy sources are used to boil water and form stream so that turbines can rotate and water to produce electricity. But with application of solar energy heat of sun can boil that water to create steam and rotate turbines. To convert sunlight into electricity solar panels, photoelectric technologies and thermoelectric technologies etc are used.

2. Homes: Use of solar energy is increasing in homes as well. Residential appliances can easily use electricity generated through solar power. Besides this solar energy is running solar heater to supply hot water in homes. Through photovoltaic cell installed on the roof of the house energy is captured and stored on batteries to use throughout the day at homes for different purposes. In this ways expenditure on energy is cutting down by home users.

3. Commercial use: on roofs of different buildings we can find glass PV modules or any other kind of solar panel. These panels are used there to supply electricity to different offices or other parts of building in a reliable manner. These panels collect solar energy from sun, convert it into electricity and allow offices to use their own electrical power for different purposes.

4. Ventilation system: at many places solar energy is used for ventilation purposes. It helps in running bath fans, floor fans, and ceiling fans in buildings. Fans run almost every time in a building to control moisture, and smell and in homes to take heat out of the kitchen. It can add heavy amount on the utility bills, to cut down these bills solar energy is used for ventilation purposes.

5. Power pump: solar power not just help in improving ventilation system at your homes but with that it can also help in circulating water in any building. You can connect 6- power pump with solar power supply unit but you must run it on DC current so that water circulate throughout your home.

6. Swimming pools: swimming pools are great joy for kids and adults in all seasons. But during winters it is tough to keep water hot in these pools with minimum power usage. Solar energy can help many in this matter as well. You can add a solar blanket in the pool that will keep the water hot with energy generated from sunlight. Besides this you can install a solar hot water heating system with solar hot water heating panels.

7. Solar Lighting: these lights are also known as day lighting, and work with help of solar power. These lights store natural energy of sun in day time and then convert this energy into electricity to light up in night time. Use of this system is reducing load form local power plants.

8. Solar Cars: it is an electrical vehicle which is recharged form solar energy or sunlight. Solar panels are used on this car that absorb light and then convert it into electrical energy. This electrical energy is stored in batteries used with the car, so that in night time as well we can drive these vehicles.

9. Remote applications: Remote buildings are taking benefit of solar energy at vast scale. Remote schools, community halls, and clinics can take solar panel and batteries with them anywhere to produce and use electric power.

Next-generation solar cells could be infinitely mosre useful thanks to a newly discovered nanotube structure capable of transporting electrical charges 100 million times higher than previously measured. Most solar cells currently use silicon to absorb light, however inefficiencies in the material have led scientists to develop carbon nanotubes that can be implemented to enhance the light absorption capabilities of current cells. However, until now the nanotubes have been randomly placed within the solar cells in suboptimal structures as they are difficult to arrange. A new generation of solar panels made from a mineral called perovskite has the potential to convert solar energy into household electricity more cheaply than ever before, according to a study from Briain's Exeter University.

Super-thin, custom-colored panels attached to a building's windows may become a "holy grail" for India and African countries, Senthilarasu Sundaram, one of the authors of the study, told the Thomson Reuters Foundation. In those countries these types of material will be like a holy grail: they can both shade windows and at the same time produce electricity. With a thickness measured in billionths of a meter, 
solar panels made of perovskite will be more than 40 percent cheaper and 50 percent more efficient than those commercially produced today. Unlike other solar panels, those made of perovskite can absorb most of the solar spectrum and work in various atmospheric conditions, rather than only in direct sunlight. "This type of material for solar cells works in diffused conditions much, much better than the other types of solar cells," said Sundaram. "It won't be 100 percent, but it will be much more than what we have now." Researchers have already tested the material in the Americas, Asia, Europe and the Middle East. Current commercial products used to generate solar power, such as silicon or thinfilm based technologies, are expensive because they are processed using vacuum-based techniques, the Exeter study said. The production process for perovskite panels is very straightforward, but researchers still have to test the material under different conditions to better understand its properties, before companies embark on industrial-scale production, it said. The photovoltaic (PV) energy market has been growing because of government targets for renewable energy production and $\mathrm{CO} 2$ emission controls, and the International Energy Agency has said that solar energy could be the world's biggest source of electricity by 2050 .

\section{References}

[1] http://www.chemistryexplained.com/Ru-Sp/Solar-Cells.html

[2] http://www.solarstik.com/stikopedia/stiktm-u

[3] Ciesielskia, Peter N; Frederick M. Hijazib, Amanda M. Scott, Christopher J. Faulkner, Lisa Beard, Kevin Emmett, Sandra J. Rosenthal, David Cliffel, G. Kane Jennings (May 2010). "photosystem I- Based biohybrid phtoelectrochemical cells". $\begin{array}{llll}\text { Biosource Technology } 101 & \text { (9): 3047-3053. }\end{array}$ doi:10.1016/j.biortech.2009.12.045. Retrieved 24 October 2013.

[4] Yehezkeli, Omer; Ran Tel-Vered, Julian Wasserman, Alexander Trifonov, Dorit Michaeli, Rachel Nechushtai, Itamar Willner (13 March 2012). "Integrated photosytem IIBased photoelectrochemical cells". Nature communication. doi:10.1038/ncomms 1741 .

[5] Wohlgemuth JH, Narayanan S. Buried contact concentrator solar cells. Twenty Second IEEE Photovoltaic Specialists Conference. $1991 ; 1: 273-277$.

[6] "Publications, Presentations, and News Database: Cadmium Telluride". National Renewable Energy Laboratory.

[7] K. Zweibel, J. Mason, V. Fthenakis, "A Solar Grand Plan", Scientific American, Jan 2008. CdTe PV is the cheapest example of PV technologies and prices are about $16 \notin / \mathrm{kWh}$ with US Southwest sunlight.

[8] Further mention of cost competitiveness: "Solar Power Lightens Up with Thin-Film Technology", Scientific American, April 2008.

[9] Peng et al. (2013). "Review on life cycle assessment of energy payback and greenhouse gas emission of solar photovoltaic systems". Renewable and Sustainable Energy Reviews 19: 255-274. doi:10.1016/j.rser.2012.11.035.
[10] V. Fthenakis and H. C. Kim. (2010). "Life-cycle uses of water in U.S. electricity generation". Renewable and Sustainable Energy Reviews 14: 2039-2048. doi:10.1016/j.rser.2010.03.008.

[11] de Wild-Scholten, Mariska (2013). "Energy payback time and carbon footprint of commercial photovoltaic systems". Solar Energy Materials \& Solar Cells 119: 296-305. doi:10.1016/j.solmat.2013.08.037.

[12] Fthenakis, Vasilis M. (2004). "Life cycle impact analysis of cadmium in CdTe PV production" (PDF). Renewable and Sustainable Energy Reviews 8 (4): 303-334. doi:10.1016/j.rser.2003.12.001. Archived from the original on 23 September 2014.

[13] Werner, Jürgen H. (2 November 2011). "Toxic Substances In Photovoltaic Modules". postfreemarket.net. Institute of Photovoltaics, University of Stuttgart, Germany - The 21st International Photovoltaic Science and Engineering Conference 2011 Fukuoka, Japan. p. 2. Archived from the original (PDF) on 23 September 2014. Retrieved 23 September 2014.

[14] "Water Solubility of Cadmium Telluride in a Glass-to-Glass Sealed PV Module" (PDF). Vitreous State Laboratory, and AMELIO Solar, Inc. 2011.

[15] Herman Trabish, The Lowdown on the Safety of First Solar's CdTe Thin Film, greentechmedia.com March 19, 2012

[16] Robert Mullins, Cadmium: The Dark Side of Thin-Film?, September 25, 2008

[17] Supply Constraints Analysis, National Renewable Energy Laboratory

[18] Fraunhofer ISE Photovoltaics Report, July 28, 2014, pages 18,19

[19] http://www.solar-facts-and-advice.com/amorphoussilicon.html

[20] http://www.iea.org (2014). "Technology Roadmap: Solar Photovoltaic Energy" (PDF). IEA. Archived from the original on 7 October 2014. Retrieved 7 October 2014.

[21] Fraunhofer ISE and NREL (January 2015). "Current Status of Concentrator Photovoltaic (CPV) Technology" (PDF). Archived from the original on 25 April 2015. Retrieved 25 April 2015.

[22] "DOE Solar Energy Technologies Program Peer Review" (PDF). U.S. department of energy 2009. Retrieved 10 February 2011.

[23] Wan, Haiying "Dye Sensitized Solar Cells", University of Alabama Department of Chemistry, p. 3

[24] "Dye-Sensitized vs. Thin Film Solar Cells", European Institute for Energy Research, 30 June 2006

[25] Tributsch, H (2004). "Dye sensitization solar cells: a critical assessment of the learning curve". Coordination Chemistry Reviews 248 (13-14): 1511. doi:10.1016/j.ccr.2004.05.030.

[26] Moss, S. J. and Ledwith, A. (1987). The Chemistry of the Semiconductor Industry. Springer. ISBN 0-216-92005-1.

[27] Milliron, Delia J.; Gur, Ilan; Alivisatos, A. Paul (2005). "Hybrid Organic-Nanocrystal Solar Cells". MRS Bulletin 30: 41-44. doi:10.1557/mrs2005.8. 
[28] Shaheen, Sean E.; Ginley, David S.; Jabbour, Ghassan E. (2005). "Organic-Based Photovoltaics". MRS Bulletin 30: 10. doi:10.1557/mrs2005.2.

[29] Saunders, B.R.; Turner, M.L. (2008). "Nanoparticle-polymer photovoltaic cells". Advances in Colloid and Interface Science 138 (1): 1-23. doi:10.1016/j.cis.2007.09.001. PMID 17976501 .

[30] Sariciftci, N.S.; Smilowitz, L.; Heeger, A.J.; and Wudl, F. (1993). "Semiconducting polymers (as donors) and buckminsterfullerene (as acceptor): photoinduced electron transfer and heterojunction devices". Synthetic Metals 59 (3): 333-352. doi:10.1016/0379-6779(93)91166-Y.

[31] Ginger, D.S.; Greenham, N.C. (1999). "Photoinduced electron transfer from conjugated polymers to CdSe nanocrystals".

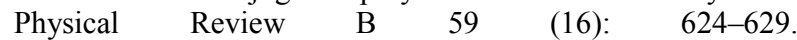
Bibcode:1999PhRvB..5910622G. doi:10.1103/PhysRevB.59.10622.

[32] Shaw, P.E.; Ruseckas, A.; Samuel, I.D.W (2008). "Exciton Diffusion Measurements in Poly(3-hexylthiophene)". Advanced Materials 20 (18): 3516-3520. doi:10.1002/adma.200800982.

[33] Michael G Debije, Paul P C Verbunt, Pradeep J Nadkarni, Suresh Velate, Kankan Bhaumik, Sankaran Nedumbamana, Brenda C Rowan, Bryce S Richards and Theo L Hoeks. Promising fluorescent dye for solar energy conversion based on a perylene perinone. Applied Optics 50(2):163-169, 2011.

[34] Michael G Debije, Paul P C Verbunt, Brenda C Rowan, Bryce $\mathrm{S}$ Richards and Theo L Hoeks. Measured surface loss from luminescent solar concentrator waveguides. Applied Optics 47(36):6763-6768, 2008.

[35] K R McIntosh, N Yamada and B S Richards. Theoretical comparison of cylindrical and square-planar luminescent solar concentrators. Applied Physics B-Lasers and Optics 88(2):285-290, 2007.

[36] Reisfeld, Renata; Neuman, Samuel (July 13, 1978). "Planar solar energy converter and concentrator based on uranyldoped glass". Nature 274: 144-145. doi:10.1038/274144a0.

[37] Reisfeld, Renata; Kalisky, Yehoshua (1980). "Improved planar solar converter based on uranyl neodymium and holmium glasses". Nature 283 (5744): 281-282. doi:10.1038/283281a0.

[38] W.Heywang, K.H.Zaininger, Silicon: the semiconductor material, in Silicon: evolution and future of a technology, P.Siffert, E.F.Krimmel eds., Springer Verlag, 2004.

[39] Green, Martin A. (2003). Third Generation Photovoltaics: Advanced Solar Energy Conversion. Springer. p. 65.

[40] "New South Innovations News - UNSW breaks solar cell record". NewSouth Innovations. 2008-11-18. Retrieved 201206-23.[dead link]

[41] "Solar Junction Breaks Concentrated Solar World Record with 43.5\% Efficiency". Cnet.com.

[42] "Sharp Hits Concentrator Solar Cell Efficiency Record, $43.5 \% "$

[43] N. Gupta, G. F. Alapatt, R. Podila, R. Singh, K.F. Poole, (2009). "Prospects of Nanostructure-Based Solar Cells for Manufacturing Future Generations of Photovoltaic Modules". International Journal of Photoenergy 2009: 1. doi:10.1155/2009/154059.

[44] Eperon, Giles E.; Stranks, Samuel D.; Menelaou, Christopher; Johnston, Michael B.; Herz, Laura M.; Snaith, Henry J. (2014). "Formamidinium lead trihalide: a broadly tunable perovskite for efficient planar heterojunction solar cells". Energy \& Environmental Science 7 (3): 982. doi:10.1039/C3EE43822H.

[45] Noel, Nakita K.; Stranks, Samuel D.; Abate, Antonio; Wehrenfennig, Christian; Guarnera, Simone; Haghighirad, Amir-Abbas; Sadhanala, Aditya; Eperon, Giles E.; Pathak, Sandeep K.; Johnston, Michael B.; Petrozza, Annamaria; Herz, Laura M.; Snaith, Henry J. (1 May 2014). "Lead-free organicinorganic tin halide perovskites for photovoltaic applications". Energy \& Environmental Science 7 (9): 3061. doi:10.1039/C4EE01076K.

[46] "Civil Engineering (May 13, 2014)".

[47] "Solar Reviews (May 05, 2014)".

[48] "Industry Market Trends." Is Perovskite the Future of Solar Cells? N.p., 06 Dec. 2013. Web. 21 Jan. 2015.

[49] Feng, Wenchun, and Garfunkel Group. "Perovskite Solar Cells." Rutgers University. 07 Mar. 2014. Lecture.

[50] Snaith, Henry J. "Perovskites: The Emergence of a New Era for Low-Cost, High-Efficiency Solar Cells." The Journal of Physical Chemistry Letters4.21 (2013): 3623-630. Web.

[51] Jeon, Nam Joong, Jun Hong Noh, Young Chang Kim, Woon Seok Yang, Seungchan Ryu, and Sang Il Seok. "Solvent Engineering for High-performance Inorganic-organic Hybrid Perovskite Solar Cells." Nature Materials 13 (2014): 897-903. Web. 21 Jan. 2015.

[52] Yuanyuan Zhou, Mengjin Yang, Wenwen Wu, Alexander L. Vasiliev, Kai Zhu, Nitin P Padture. "Room-Temperature Crystallization of Hybrid-Perovskite Thin Films via SolventSolvent Extraction for High-Performance Solar Cells." J. Mater. Chem. A (2015), DOI: 10.1039/C5TA00477B

[53] Chen, Qi, Huanping Zhou, Ziruo Hong, Song Luo, HsinSheng Duan, Hsin-Hua Wang, Yongsheng Liu, Gang Li, and Yang Yang. "Planar Heterojunction Perovskite Solar Cells via Vapor-Assisted Solution Process." Journal of the American Chemical Society 136.2 (2014): 622-25. Web.

[54] Liu, Mingzhen, Michael B. Johnston, and Henry J. Snaith. "Efficient Planar Heterojunction Perovskite Solar Cells by Vapour Deposition." Nature501.7467 (2013): 395-98. Web.

[55] Gratzel, M. Nature, 414, 338-344 (2001).

[56] Khaselev \& Turner. Science, 280, 425-427 (1998).

[57] Licht, S. J. Phys. Chem. 105, 6281-6294 (2001).

[58] Nowotny, J and T. Bak. Int. J of Hydrogen Economy, 30, 521544 (2005).

[59] Green et. al., Progress in Photovoltaics: Research and Applications 2012 10.1002/pip.2163

[60] Gevorgyan et. al., Solar Energy Materials and Solar Cells 2013 10.1016/j.solmat.2013.04.024

[61] Krebs et. al., Progress in Photovoltaics: Research and Applications 2007 10.1002/pip.794 
[62] Krebs et. al., Energy Technology 2013 10.1002/ente.201300057

[63] Green et. al., Progress in Photovoltaics: Research and Applications 2012 10.1002/pip.2163

[64] Jorgensen et. al., Solar Energy Materials and Solar Cells 2008 10.1016/j.solmat.2008.01.005

[65] Krebs et. al., Solar Energy Materials and Solar Cells 2009 10.1016/j.solmat.2008.10.004

[66] Brabec et. al., Solar Energy Materials and Solar Cells 2004 10.1016/j.solmat.2004.02.030

[67] Baskoutas, Sotirios; Terzis, Andreas F. (2006). "Sizedependent band gap of colloidal quantum dots". Journal of Applied Physics 99: 013708. Bibcode:2006JAP....99a3708B. doi:10.1063/1.2158502.

[68] H. Sargent, E. (2005). "Infrared Quantum Dots" (PDF). Advanced Materials $17 \quad$ (5): 515-522. doi:10.1002/adma.200401552.
[69] Ip, Alexander H.; Thon, Susanna M.; Hoogland, Sjoerd; Voznyy, Oleksandr; Zhitomirsky, David; Debnath, Ratan; Levina, Larissa; Rollny, Lisa R.; Carey, Graham H.; Fischer, Armin; Kemp, Kyle W.; Kramer, Illan J.; Ning, Zhijun; Labelle, André J.; Chou, Kang Wei; Amassian, Aram; Sargent, Edward H. (2012). "Hybrid passivated colloidal quantum dot solids". Nature Nanotechnology 7 (9): 577-582. Bibcode:2012NatNa...7...577I. doi:10.1038/nnano.2012.127. PMID 22842552.

[70] Mitchell, Marit (2014-06-09). "New nanoparticles bring cheaper, lighter solar cells outdoors". Rdmag.com. Retrieved 2014-08-24.

[71] "Photovoltaics Report". Fraunhofer ISE. 28 July 2014. Archived from the original (PDF) on 31 August 2014. Retrieved 31 August 2014. 